\title{
Influence of Adhesion Properties on the Crash Behavior of Steel/Polymer/Steel Sandwich Crashboxes: An Experimental Study
}

\author{
Mohamed Harhash 1,2,3,*(D), Moritz Kuhtz ${ }^{4} \mathbb{D}$, Jonas Richter ${ }^{4}$, Andreas Hornig ${ }^{4} \mathbb{D}$, Maik Gude ${ }^{4} \mathbb{D}$ \\ and Heinz Palkowski ${ }^{1}$ (D) \\ 1 Institute of Metallurgy (IMET), Clausthal University of Technology, 38678 Clausthal-Zellerfeld, Germany; \\ heinz.palkowski@tu-clausthal.de \\ 2 Clausthal Centre for Material Technology (CZM), Clausthal University of Technology, \\ 38678 Clausthal-Zellerfeld, Germany \\ 3 Department of Metallurgical and Materials Engineering, Faculty of Petroleum and Mining Engineering, \\ Suez University, Suez 43512, Egypt \\ 4 Institute of Lightweight Engineering and Polymer Technology (ILK), Technische Universität Dresden, \\ 01307 Dresden, Germany; moritz.kuhtz@tu-dresden.de (M.K.); jonas.richter@tu-dresden.de (J.R.); \\ andreas.hornig@tu-dresden.de (A.H.); maik.gude@tu-dresden.de (M.G.) \\ * Correspondence: mohamed.harhash@tu-clausthal.de; Tel.: +49-5323-722219
}

Citation: Harhash, M.; Kuhtz, M.; Richter, J.; Hornig, A.; Gude, M.; Palkowski, H. Influence of Adhesion Properties on the Crash Behavior of Steel/Polymer/Steel Sandwich Crashboxes: An Experimental Study. Metals 2021, 11, 1400. https:// doi.org/10.3390/met11091400

Received: 4 August 2021

Accepted: 3 September 2021

Published: 4 September 2021

Publisher's Note: MDPI stays neutral with regard to jurisdictional claims in published maps and institutional affiliations.

Copyright: (c) 2021 by the authors. Licensee MDPI, Basel, Switzerland. This article is an open access article distributed under the terms and conditions of the Creative Commons Attribution (CC BY) license (https:// creativecommons.org/licenses/by/ $4.0 /)$.

\begin{abstract}
The energy absorption behavior of crashboxes made of steel/polymer/steel (SPS) sandwich sheets can be influenced by numerous parameters, such as the materials used, their thicknesses and stacking, and the adhesion properties between their layers. Therefore, in the present study, the impact of steel/polymer adhesion quality on the occurring failure modes of the crashboxes and the resulting energy absorptions are experimentally analyzed. For this purpose, axial crushing and three-point bending tests on double-hat and top-hat crash boxes were performed, respectively. Three levels of adhesion quality are investigated: none, weak, and strong adhesion strengths. Additionally, the structural crash properties, such as energy absorption and maximal intrusion, are determined and analyzed at both of the quasi-static and highly dynamic loading rates. The results of these investigations show that the adhesion strengths chosen here significantly influence both the failure modes and the energy absorption values. In particular, the structural parameters, in the case of no adhesion, are at most half of those in the case of strong adhesion. However, it is also shown that, in the case of weak adhesion, the structural characteristics are slightly reduced. Based on these results, the possibility to adjust the adhesion strength—globally and/or locally-could be used in future activities to purposefully tailor the failure behavior of hybrid crashboxes.
\end{abstract}

Keywords: lap shear strength; axial crushing test; bending test; sandwich composites; adhesion properties; top-hat and double-hat crashboxes

\section{Introduction}

Sheet-like steel/polymer/steel (SPS) sandwich composites were developed due to their attracting applicability in the automotive industry, where weight saving and, consequently, less fuel consumption can be achieved. Further considerable advantages for this material class are their improved acoustic and thermal damping properties. SPS products such as Litecor ${ }^{\circledR}$ could be applied in several sheet parts in the body-in-white $[1,2]$.

The property profile of structures made of SPS sheets can be controlled not only by selecting the type of skin and core materials and their thicknesses but also by manipulating the adhesion properties between the skin and core layers. For instance, the damping behavior is strongly affected by the thickness of the skin and core layers [3].

Moreover, SPS sheets proved their successful applicability as crash absorbers, where they could be formed into hat-shapes and joined mechanically and by gluing to deliver 
crashboxes. Moreover, their crushing behavior was studied in, e.g., [4-6], and has shown comparable failure modes (e.g., progressive asymmetric folding in the case of double-hat crashboxes) to the traditional steel-based crashboxes. This successful failure mode could be achieved by (a) selecting skin and core layers possessing good formability at room temperature and (b) improving the skin/core layer adhesion strength. In the previous literature [4-6], the SPS in the crashboxes were prepared, so that they possessed a high (or, rather, the best-possible) adhesion strength. However, a deep understanding of the influence of the adhesion strength on the failure modes under highly dynamic as well as quasi-static conditions is still missed and is described in the current paper.

The adhesion strength had shown a significant influence on the forming limits and the damage behavior of aluminum/polyethylene/aluminum (Al/PE/Al) sandwich sheets, which was investigated experimentally and numerically in [7]. It was found that, by increasing the $\mathrm{Al} / \mathrm{PE}$ adhesion strength, the damage could be postponed, and accordingly, the level of the forming limit curve (FLC) was improved and shifted to higher values.

Additionally, the adhesion strength significantly influenced the tensile properties; with good bonding, the rule of mixtures could be applied to estimate those tensile properties [8]. Moreover, the springback angle was reduced under bending by improving the adhesion strength and becomes similar to a monolithic sheet [9]. With improved adhesion properties, the deep-drawability could be enhanced as well [10-12]. It could, additionally, be reported in [13] that the mechanical response of composite structures can be tailored by controlling the interface properties.

The aim and the novelty of this paper are to investigate and quantify the influence of the skin/core adhesion strength on the structural properties of crash-relevant components under axial crushing and bending loading of double-hat and top-hat crashboxes, respectively. Quasi-static and highly dynamic loading rates are considered. The adhesion strength is varied by changing the processing conditions of the adhesive agent, such as curing temperature and time. The results are presented in terms of force-displacement curves and energy absorption behavior in addition to a detailed graphical representation of the failure progress and its relationship with the adhesion strength.

\section{Materials and Methods}

\subsection{Materials and Adhesion Properties}

In order to achieve the above-mentioned aims, the following materials were used:

- Skin sheet: a high strength, formable steel sheet grade was utilized as skin sheets for the foreseen sandwich composites, namely an electrolytic galvanized $0.48 \mathrm{~mm}$ thick DPK 30/50 + ZE (HCT500X, grade number: 1.0939 according to DIN 10346:200907 [14], thyssenkrupp Steel Europe AG, Duisburg, Germany).

- Core layer: a thermoplastic polyolefin (PP/PE) with $0.6 \mathrm{~mm}$ thickness was considered (Konrad Hornschuh AG, Weißbach, Germany).

- Adhesive agent: one-component epoxy resin Köratac FL201 (Kömmerling Chemische Fabrik GmbH, Pirmasens, Germany) was used. The properties of this agent are previously given by the authors in [15].

Based on this, symmetric SPS sheets of thickness combination 0.48/0.6/0.48 are produced. The mechanical properties of the monomaterials (steel and polymer) and resulting SPS sandwich sheet as obtained by uniaxial tensile testing at $0.005 \mathrm{~s}^{-1}$ were determined earlier and published in [5].

The peak metal temperature (PMT) of this adhesive agent is specified by the producer to be in the range of $216-241{ }^{\circ} \mathrm{C}$ to deliver strong adhesion strength results during the so-called "coil coating" process [16]. PMT is the temperature at which the adhesive agent should be cured after spreading it with a thickness of approximately $10 \mu \mathrm{m}$ on the metallic sheet. Later, the coated metallic sheet can be bonded to the polymer core. SPS are produced by means of a two-step roll-bonding process of the laboratory facilities, as described in [17]. Based on the PMT value, the test plan given in Table 1 is designed, where a full factorial plan is followed. Two factors were considered: (a) temperature ( $T$ ), in three stages of 230, 
260 , and $290{ }^{\circ} \mathrm{C}$, and (b) time (t), in three stages of 1,3 , and $5 \mathrm{~min}$. Therefore, nine test conditions are foreseen with five replications per test condition. The adhesion strength is evaluated via single lap shear test according to ASTM D 3165 with a specimen width of $25 \mathrm{~mm}$, an overlapping length of $5 \mathrm{~mm}$, and a constant loading rate of $1 \mathrm{~mm} / \mathrm{min}$. An exemplarily correlation between the holding time $(1,3$, and $5 \mathrm{~min})$ with the lap shear strength is shown in Figure 1 for $T=260{ }^{\circ} \mathrm{C}$. Moreover, the lap shear strength results in correlation with the tested processing conditions are listed in Table 1 and represented in the contour chart in Figure 2a. As a result, by varying the processing conditions, different bond strength values are obtained, ranging from $0 \mathrm{MPa}$ to $10.7 \mathrm{MPa}$, which is the best-possible strength value corresponding to the maximum shear strength of the polymer core. Based on these results, adhesion is not possible at a higher temperature of $290{ }^{\circ} \mathrm{C}$ and a holding time $>1$ min due to the over-curing of the adhesive agent. The maximum adhesion strength is reached at $T=260^{\circ} \mathrm{C}$ with holding times starting from $3 \mathrm{~min}$.

Table 1. Lap shear strength values according to the test plan based on varying the processing conditions of the adhesive agent (at least five specimens per condition were tested).

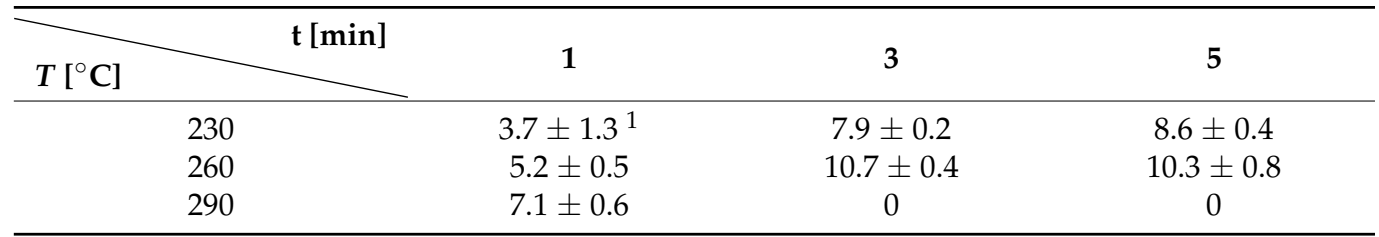

${ }^{1}$ All values in the table represent the maximum lap shear strength in MPa, obtained from Figure 1a.

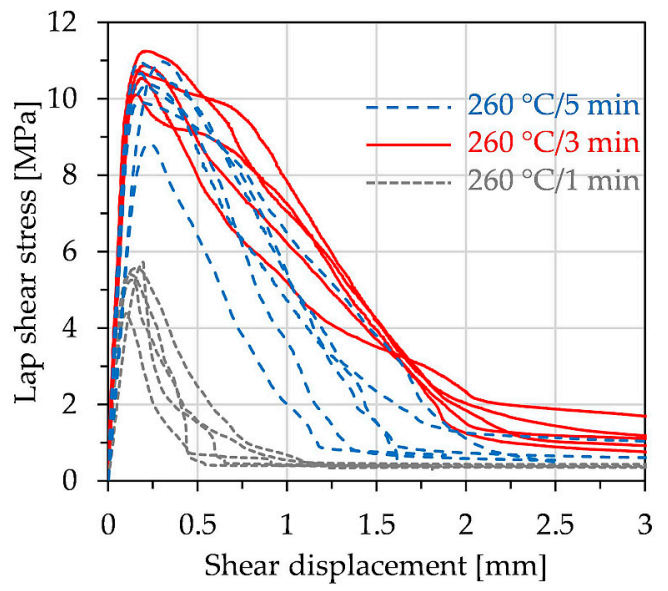

(a)

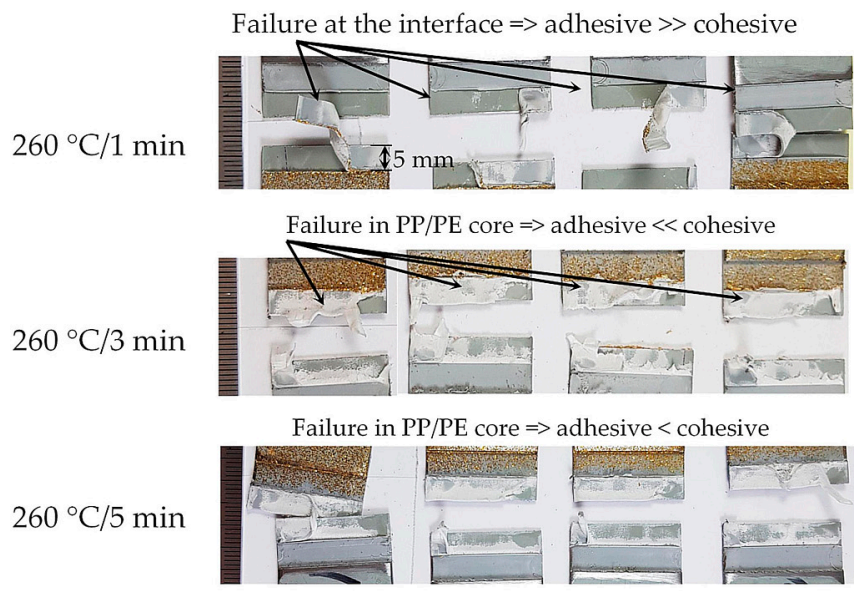

(b)

Figure 1. (a) Exemplarily representation of the effect of the holding time on the adhesion strength at $T=260{ }^{\circ} \mathrm{C}$ for three curing times $(1,3$, and $5 \mathrm{~min})$ and (b) failure images after the lap shear test showing the cohesive and adhesive failure fractions.

In order to perform the subsequent structural tests, two lap shear strength $(\tau)$ values have been selected, in addition to one condition without adhesion between the SPS layers, i.e., at $\tau=0 \mathrm{MPa}$, namely:

- The maximum adhesion was at $\tau=10.7 \pm 0.4 \mathrm{MPa}$, which could be reached at $260{ }^{\circ} \mathrm{C} / 3 \mathrm{~min}$. With this condition, a reproducible cohesive failure mode is achieved, as seen in Figure 1b. This will be notated as "strong" adhesion for a better representation of the results.

- Weak adhesion (approx. $50 \%$ of the strong one) was at $\tau=5.2 \pm 0.5 \mathrm{MPa}$, which could be reached at $260{ }^{\circ} \mathrm{C} / 1 \mathrm{~min}$. In this case, the adhesive failure is dominant (see Figure 1a). 


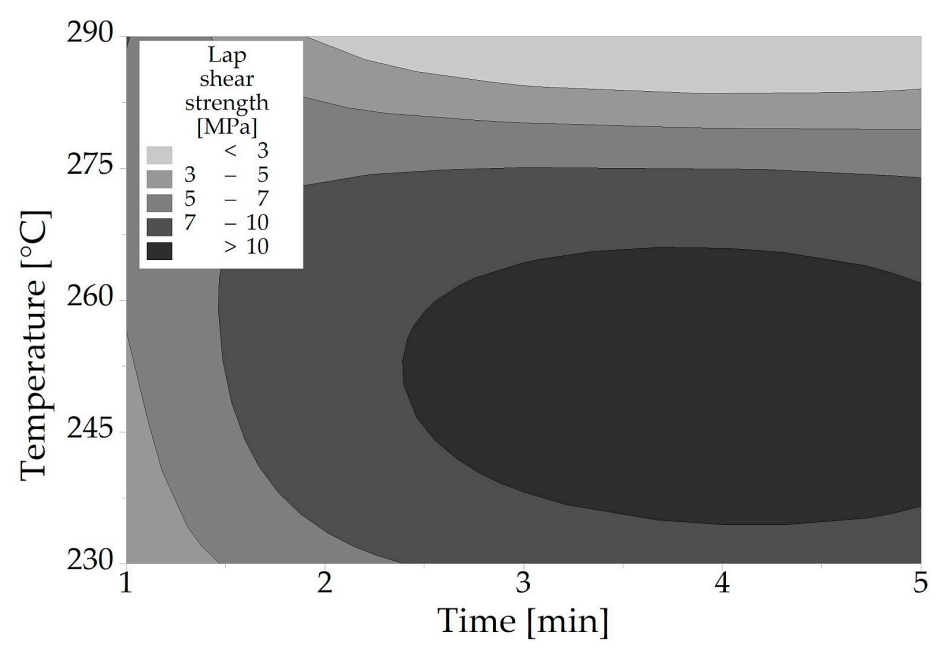

(a)

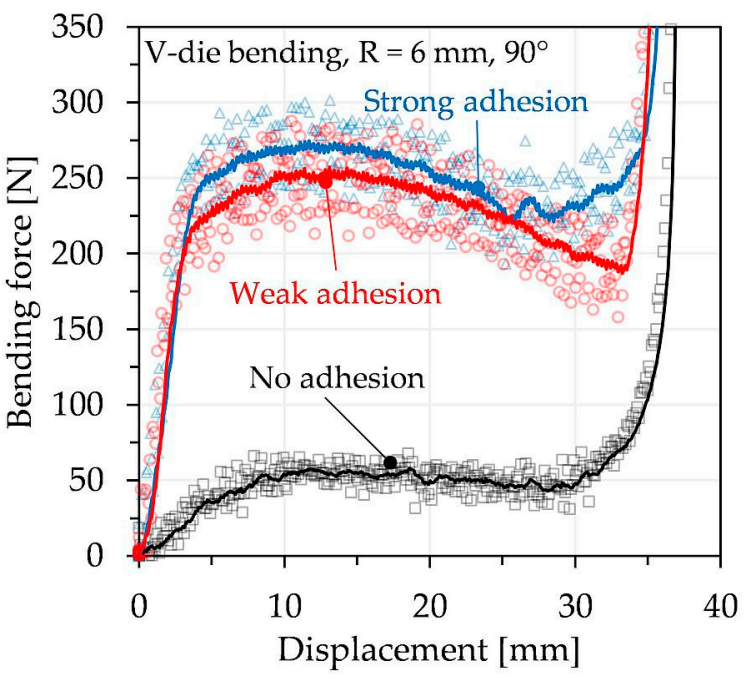

(b) 1

${ }^{1}$ : the measured force-displacement data are smoothed through an average function with a 10 points step.

Figure 2. (a) Contour chart showing a summary of the lap shear results in correlation with the processing temperature and time. (b) Influence of the adhesions strength on the V-die bending behavior of $100 \times 20 \mathrm{~mm}^{2}$ specimens.

Bending tests, using a $90^{\circ} \mathrm{V}$-die, were performed on a standard specimen size of $100 \times 20 \mathrm{~mm}^{2}$ to analyze the influence of the adhesion on the bending strength and springback on this specimen size level. This approach is useful for understanding bending behavior on the structural level, as is discussed mainly in this paper. Figure $2 b$ shows the results of the $\mathrm{V}$-die bending utilizing a $5 \mathrm{~mm}$ radius punch tip. The results show that the stiffness (in the elastic region) and the maximum bending force of the specimens without adhesion $(\sim 60 \mathrm{~N})$ is much less than that of the specimens with weak $(\sim 250 \mathrm{~N})$ or strong adhesion $(\sim 270 \mathrm{~N})$. The specimens of weak and strong adhesion show comparable stiffness; however, the maximum bending force was slightly higher in the case of the strong adhesion specimen. Significant springback angles of $>10^{\circ}$ are found for the specimens without adhesion, in comparison to $<8^{\circ}$ for the others with the strong adhesion. This can be attributed to the absence of the steel/polymer interlayer shear strength, which is responsible for achieving and improving stiffness and strength as well as stability (in terms of the springback). This result is in good correlation with those of the literature [9,10]. As a result of the adhesion quality, further phenomena appeared on the structural level, e.g., global buckling instead of the desired progressive folding, as discussed later in Section 3.

\subsection{Crashbox Preparation}

Two types of crashboxes are considered in this study: a) top-hat and b) double-hat crashboxes, as illustrated in Figure $3 a, b$, respectively. The inner cross-section area of the investigated hat profiles used to prepare either the top-hat or the double-hat crashboxes is $75 \times 37.5 \mathrm{~mm}^{2}$ with a length of $300 \mathrm{~mm}$. The flange size for the $1.56 \mathrm{~mm}$ thick SPS $(0.48 / 0.6 / 0.48)$ is $21 \mathrm{~mm}$. The hat shape geometry is shown in detail in Figure 3a. The flat SPS sheet is processed into the hat shapes by bending using a press brake bending machine with a $6 \mathrm{~mm}$ bend radius. After bending, joining the crashboxes is accomplished: (a) SPS hat profile with an SPS cover sheet to deliver the top-hat crashbox (Figure 3a) and (b) two SPS hat profiles together to deliver the double-hat crashbox (Figure $3 b$ ). Joining is performed using a combined joining technology, in which adhesion promoter (2-component epoxy resin: $3 \mathrm{M}$ Scotch-Weld ${ }^{\mathrm{TM}}$ DP 490 , which was cured at $65^{\circ} \mathrm{C}$ for $2 \mathrm{~h}$ ) and (b) blind riveting (using $4 \mathrm{~mm}{ }^{\varnothing}$ stainless steel rivets) are applied. In order to initiate a progressive folding in the double-hat crashboxes during the axial crushing test, a bead trigger is introduced in the top edge of the crashboxes, as shown in Figure 3b; for a detailed experimental and numerical study covering this point, see [5]. 


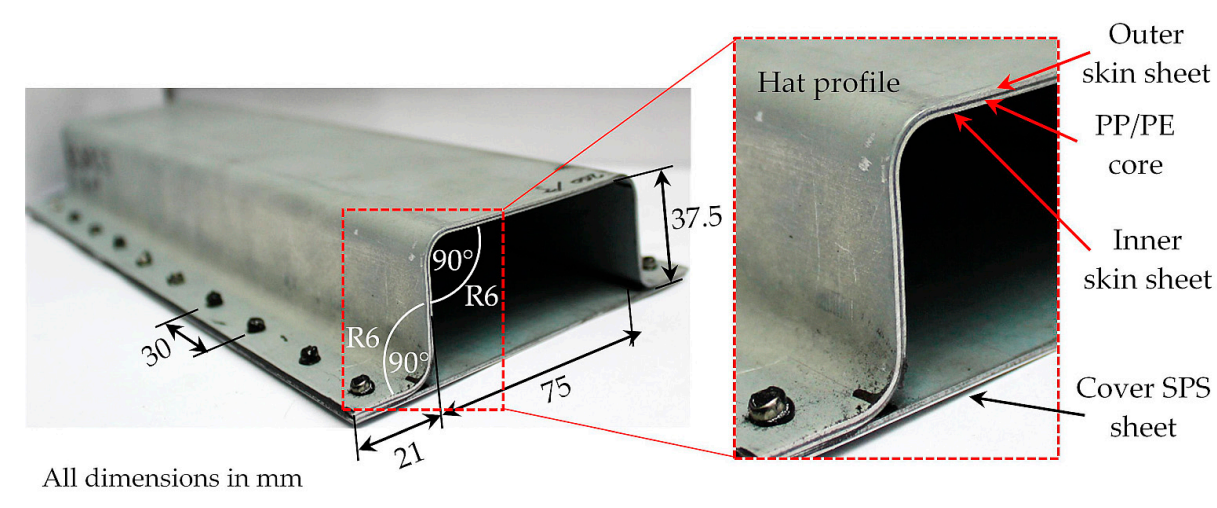

(a)

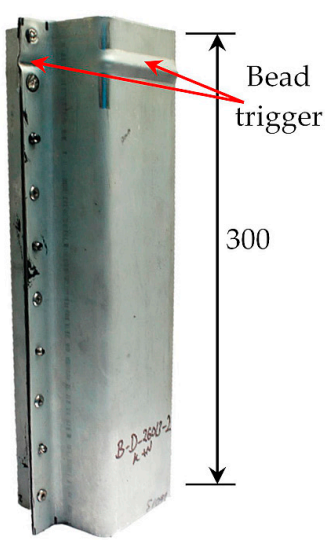

(b)

Figure 3. (a) Top-hat and (b) double-hat crashboxes.

In the case of the crashboxes without steel/polymer adhesion, a special preparation procedure is followed. The main point was to bend the three-layered SPS without adhesion between its layers. Thus, the approach is to use a double-face tape with $10 \mathrm{~mm}$ width to join the layers' boundaries only. As a result, bending is possible, where higher compensation angles during the bending have to be considered. For instance, for the SPS with strong adhesion, a compensation angle of $\sim 7^{\circ}$ is necessary to achieve the $90^{\circ}$ hat-shape; however, for the ones without adhesion, a compensation of $>10^{\circ}$ is needed. This is in coincidence with the springback results of the V-die bending mentioned earlier. Later preparation, such as joining by riveting and gluing, is the same procedure used for the other crashboxes.

\subsection{Testing Procedure and Evaluation}

Two testing methodologies were applied to investigate the influence of the adhesion on the energy absorption behavior and the failure modes, namely:

1. Axial crushing test: For the dynamic testing rate, an initial crushing velocity of approximately $30 \mathrm{~km} / \mathrm{h}$ is achieved in a drop tower with an impact mass of $156.6-292.6 \mathrm{~kg}$ and an impact height of $3.5 \mathrm{~m}$, resulting in a kinetic energy $(K E)$ of $5.4-10 \mathrm{~kJ}$, respectively, as given in Table 2. The forming forces were captured by a Kistler SmartCrash ${ }^{\circledR}$ force measuring element (type 9350A) with a maximum measuring range of $500 \mathrm{kN}$. A high-speed camera system (Photron V7.1) records the measuring field with a resolution of 768 by 976 pixels with 5000 frames per second. Later, the force-displacement curves can be determined with digital image correlation using GOM Aramis system by synchronizing the time-force results measured by the Kistler force measurement system with the high-speed camera recording. However, the quasi-static axial crushing test is performed with a constant displacement rate of $1 \mathrm{~mm} / \mathrm{s}$. For this purpose, a $1000 \mathrm{kN}$ hydraulic MAN universal testing machine is used, where the force-displacement results are captured using an iba ${ }^{\circledR}$ data acquisition and evaluation system. The axial crushing test configuration is illustrated previously in [5].

2. Three-point bending test: in this case, a $50 \mathrm{~mm}$ diameter bending punch is utilized, where the distance between the two support rollers is $200 \mathrm{~mm}$, as described in Figure 4 . This setup is applied in both the quasi-static and highly dynamic test conditions. In Figure $4 \mathrm{a}$, the highly dynamic test configuration is shown. The utilized drop mass, height, and KE are given in Table 2. For the crashboxes without adhesion, less $K E$ was applied, because less energy absorption is expected. This knowledge is gained in principle from the initial quasi-static tests. In the case of the bending tests, two Kistler load cells (the same model mentioned before) are utilized, one beneath each support roller. Using the high-speed camera, the measuring field, with a resolution of 1024 by 784 pixels at 5000 frames per second, is recorded. In addition to the SPS top-hat crashboxes, three top-hat crashboxes are prepared from only the monolithic 
steel sheets steel $(0.48 \mathrm{~mm})$ to compare its bending behavior with that of the SPS ones. In this case, a drop mass of $61.8 \mathrm{~kg}$ is applied (the same as for the SPS), but the drop height is reduced to $0.4 \mathrm{~m}$ due to the expected reduction in energy absorption. However, in the quasi-static three-point bending test, the displacement rate is kept constant at $1 \mathrm{~mm} / \mathrm{s}$ for a common displacement of $\delta=50 \mathrm{~mm}$; the test configuration is shown in Figure $4 b$.

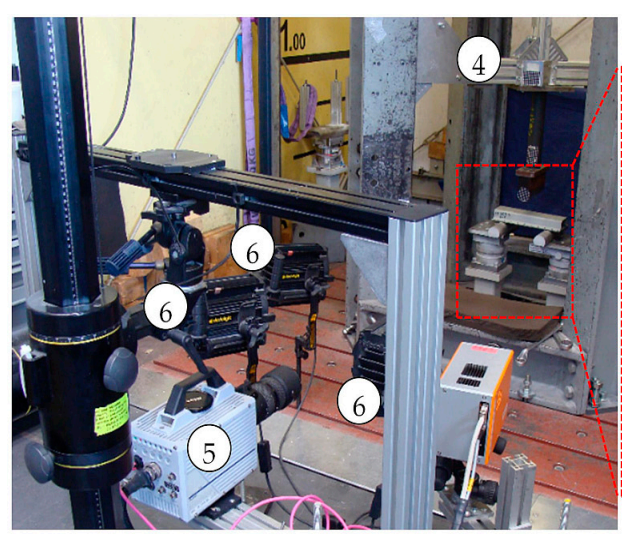

(a)

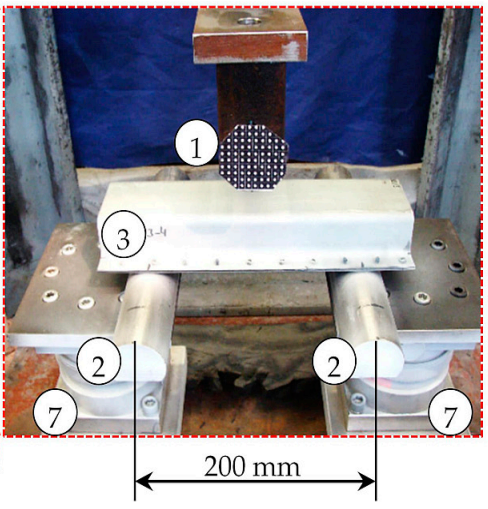

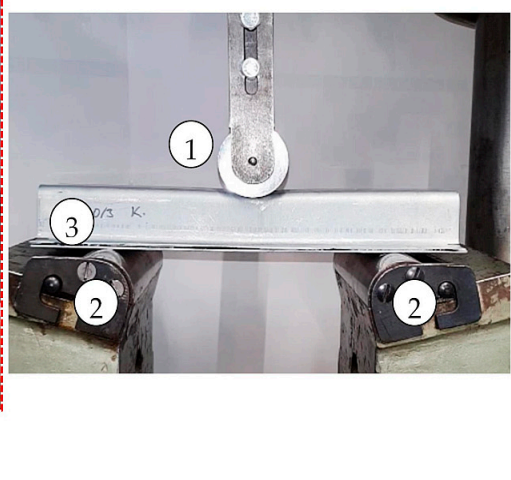

(b)

Legend:

1: $50 \mathrm{~mm} \varnothing$ bending punch, 2: $50 \mathrm{~mm}^{\varnothing}$ support rollers, 3: Top-hat crashbox, 4: Drop mass (variable),

5: High-speed camera, 6: Lightening spots, and 7: Load cell

Figure 4. (a) Highly dynamic and (b) quasi-static three-point bending test of the top-hat crashboxes.

Table 2. Experimental test program for axial crushing and three-point bending tests.

\begin{tabular}{|c|c|c|c|c|c|}
\hline \multirow[b]{2}{*}{ Test } & \multirow{2}{*}{$\begin{array}{l}\text { Loading } \\
\text { Rate }\end{array}$} & \multirow[b]{2}{*}{ Test Conditions } & \multicolumn{3}{|c|}{ Lap Shear Strength, $\tau[\mathrm{MPa}]$} \\
\hline & & & $\begin{array}{c}\text { None } \\
\tau=0 \mathrm{MPa}\end{array}$ & $\begin{array}{c}\text { Weak } \\
\tau=5.2 \mathrm{MPa}\end{array}$ & $\begin{array}{c}\text { Strong } \\
\tau=10.7 \mathrm{MPa}\end{array}$ \\
\hline \multirow{4}{*}{$\begin{array}{c}\text { Axial } \\
\text { crushing }\end{array}$} & \multirow{2}{*}{ Quasi-static } & No. of tested crashboxes & 3 & 3 & 4 \\
\hline & & Test condition & \multicolumn{3}{|c|}{$1 \mathrm{~mm} / \mathrm{s}$ until the end of progressive collapse } \\
\hline & \multirow{2}{*}{$\begin{array}{l}\text { Highly } \\
\text { dynamic }\end{array}$} & No. of tested crashboxes & 3 & 3 & 5 \\
\hline & & Test condition & $156.6 \mathrm{~kg}, 3.5 \mathrm{~m}=>K E \sim 5.4 \mathrm{~kJ}^{1}$ & $292.8 \mathrm{~kg}, 3.5$ & $=>K E \sim 10 \mathrm{~kJ}$ \\
\hline \multirow{4}{*}{$\begin{array}{c}\text { Three-point } \\
\text { bending }\end{array}$} & \multirow{2}{*}{ Quasi-static } & No. of tested crashboxes & 3 & 3 & 3 \\
\hline & & Test condition & \multicolumn{3}{|c|}{$1 \mathrm{~mm} / \mathrm{s}$, up to $\delta=50 \mathrm{~mm}$} \\
\hline & \multirow{2}{*}{$\begin{array}{l}\text { Highly } \\
\text { dynamic }\end{array}$} & No. of tested crashboxes & 3 & 3 & 5 \\
\hline & & Test condition & $61.8 \mathrm{~kg}, 0.8 \mathrm{~m}=>K E \sim 0.5 \mathrm{~kJ}$ & $61.8 \mathrm{~kg}, 1.5 \mathrm{n}$ & $=>K E \sim 0.9 \mathrm{~kJ}$ \\
\hline
\end{tabular}

\footnotetext{
${ }^{1}$ Highly dynamic test conditions in terms of the drop mass, height and accordingly the kinetic energy, respectively.
}

It is noteworthy that the deformation and failure behavior are characterized at the quasi-static and highly dynamic loading rates in order to correlate and verify the strain rate dependency of the steel and SPS sheets determined earlier in [5] by means of the uniaxial tensile testing. 
In total, 44 structural test experiments (19 quasi-static and 25 highly dynamic: 41 made of SPS and 3 made of steel sheet) are carried out on the different crashboxes. Table 2 summarizes the experimental program.

The results are obtained in terms of the force-displacement progress and, accordingly, the energy absorption to analyze the failure modes and their correlation with the adhesion strength. The main results and correlations are illustrated in Section 3; however, the photographic representation of the deformation progress at different time steps is depicted in Appendix A.

\section{Results and Discussion}

\subsection{Axial Crushing Test Results}

The influence of the adhesion quality on the structural properties after the axial crushing test with both loading rates is shown in Figure 5. From these results, the following characteristic values are determined and analyzed:

1. Peak force $\left(F_{p}\right)$ : the force value-normally the maximum value-required to create the first fold (see Figure $5 a, b)$. It is desirable to keep $F_{p}$ in the range of the mean crushing force for better impact energy absorption by reducing the impact on the passengers. This is achieved by introducing the bead triggers (see [5] for more details).

2. Mean crushing force $F_{m}$ and energy absorbed $(E A)$ : this force value is the most important value determining the $E A$ by integration for the displacement $\delta$, as given in Equation (1):

$$
E A=\int_{0}^{\delta_{\max }} F(\delta) \cdot d \delta=F_{m} \delta_{\max }
$$

3. Maximum displacement $\delta_{\text {max }}$ : as the quasi-static test is displacement controlled, the test is stopped when the progressive folding was hindered by forming of the out-ofplane failure and, accordingly, global buckling. With this, the maximum displacement $\left(\delta_{\max }\right)$ is determined. The results are listed additionally in Table 3 . The same concept is applied to the dynamic test to determine its $\delta_{\max }$. However, in the dynamic test, the used $K E$ has to be absorbed totally, as there is no possibility to stop the test when the progressive folding is hindered. In this case, the crashboxes tend to global deformation, such as sliding/falling down and global buckling. These later failure modes were especially the case for weak and no adhesion conditions.

Table 3. Summary of the axial crushing test results.

\begin{tabular}{|c|c|c|c|c|c|c|c|c|c|c|c|c|c|}
\hline \multirow{3}{*}{$\begin{array}{l}\text { Adhesion } \\
\text { Condition }\end{array}$} & \multicolumn{6}{|c|}{ Quasi-Static Rate } & \multicolumn{6}{|c|}{ Highly Dynamic Rate } & \multirow{3}{*}{$\mathbf{R}^{3}$} \\
\hline & \multicolumn{2}{|c|}{$F_{m}[\mathrm{kN}]$} & \multicolumn{2}{|c|}{$F_{p}[\mathrm{kN}]$} & \multicolumn{2}{|c|}{$\delta_{\max }[\mathrm{mm}]^{1}$} & \multicolumn{2}{|c|}{$F_{m}[\mathrm{kN}]$} & \multicolumn{2}{|c|}{$F_{p}[\mathrm{kN}]$} & \multicolumn{2}{|c|}{$\delta_{\max }[\mathrm{mm}]$} & \\
\hline & $F_{m}$ & $\Delta^{2}$ & $F_{p}$ & $\Delta^{2}$ & $\delta_{\max }$ & $\Delta^{2}$ & $F_{m}$ & $\Delta^{2}$ & $F_{p}$ & $\Delta^{2}$ & $\delta_{\max }$ & $\Delta^{2}$ & \\
\hline Strong adhesion & $55 \pm 1$ & Ref. & $74 \pm 5$ & Ref. & $172 \pm 8$ & Ref. & $69 \pm 1$ & Ref. & $105 \pm 5$ & Ref. & $158 \pm 2$ & Ref. & 1.29 \\
\hline Weak adhesion & $51 \pm 1$ & $-7 \%$ & $62 \pm 1$ & $-16 \%$ & $155 \pm 6$ & $-10 \%$ & $63 \pm 1$ & $-8 \%$ & $95 \pm 6$ & $-10 \%$ & $137 \pm 19$ & $-13 \%$ & 1.31 \\
\hline No adhesion & $27 \pm 1^{4}$ & $-51 \%$ & $49 \pm 1$ & $-21 \%$ & $91 \pm 18^{4}$ & $-47 \%$ & $33 \pm 3^{4}$ & $-52 \%$ & $60 \pm 7$ & $-44 \%$ & $120 \pm 25$ & $-24 \%$ & 1.22 \\
\hline
\end{tabular}

1: Maximum displacement for the progressive folding failure. $F_{m}$ and $F_{p}$ refer to the mean and peak crushing force, respectively, ${ }^{2}: \Delta[\%]=100$ (Value-Ref. value) $/$ Ref. value, ${ }^{3}: R=$ (Dynamic $\mathrm{F}_{\mathrm{m}} /$ Quasi-static $\mathrm{F}_{\mathrm{m}}$ ) ratio, ${ }^{4}: \mathrm{F}_{\mathrm{m}}$ in the case of $\tau=0 \mathrm{MPa}$ was determined in the range of the $\delta_{\max }$ due to the subsequent unstable folding. 
Quasi-static axial crushing results

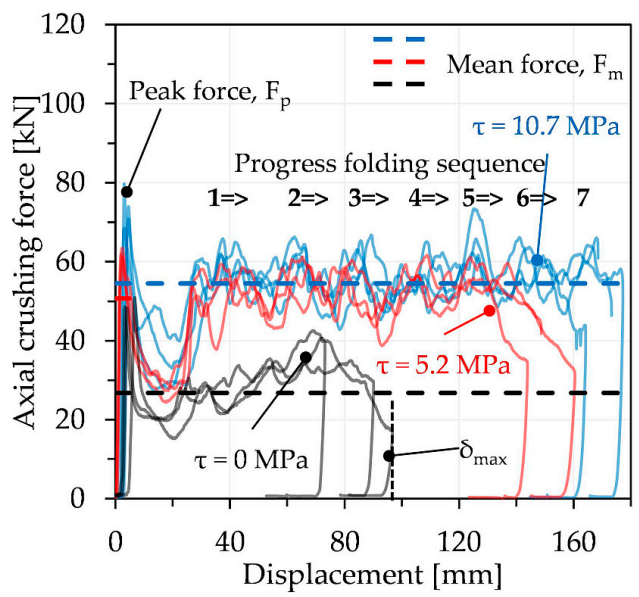

(a)

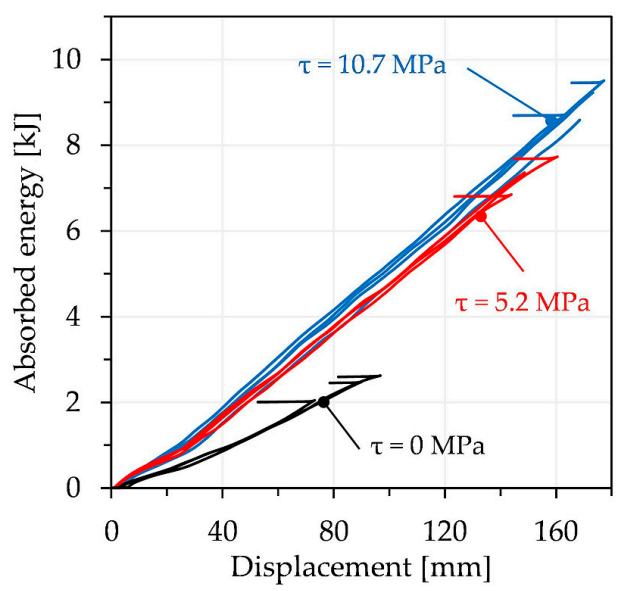

(c)

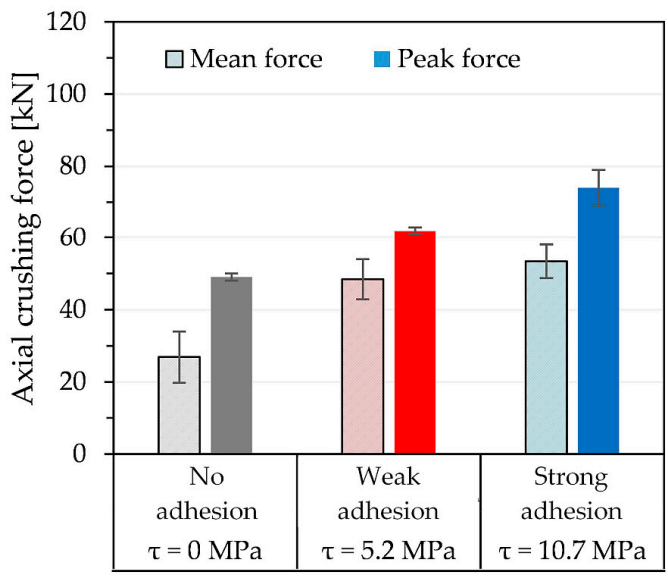

(e)
Dynamic axial crushing results

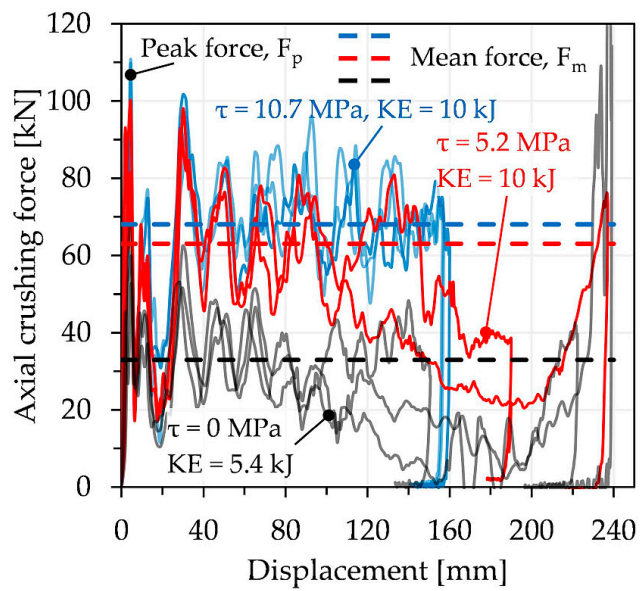

(b)

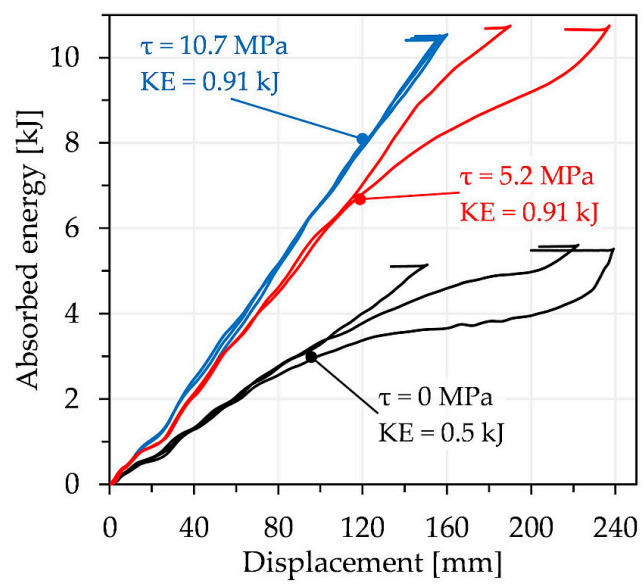

(d)

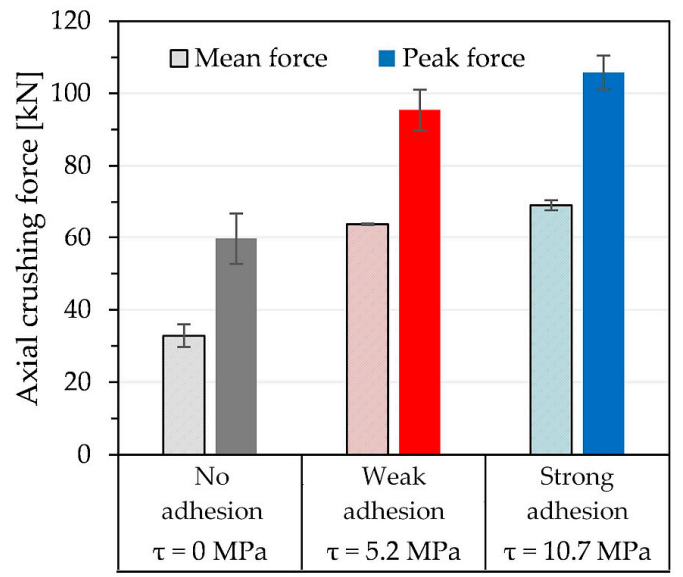

(f)

Figure 5. Axial crushing test results of the double-hat crashboxes in terms of the quasi-static (a,c) and the highly dynamic $(\mathbf{b}, \mathbf{d})$ loading rates as well as a summary of the forming force results in $(\mathbf{e}, \mathbf{f})$.

Based on this, several characteristic differences regarding the influence of the steel/ polymer adhesion quality on the resulting failure modes and energy absorption behavior can be stated and discussed, as follows:

1. In both quasi-static and dynamic loading rates, $F_{p}$ is reduced by reducing the adhesion strength. For instance, in the quasi-static loading rate, $F_{p}$ is reduced with $16 \%$ and 
$21 \%$ for the crashboxes with weak and no adhesion, respectively, as given in the left columns of Table 3. Moreover, the reduction in $F_{p}$ in the dynamic test is higher than that in the quasi-static one; the reduction reached $44 \%$ in the case of no adhesion. However, the crashboxes with weak adhesion show a reduction of only $10 \%$, as shown in Figure $5 \mathrm{f}$. This can be considered one of the advantages of utilizing a weakened adhesion as a trigger for purposefully reducing $F_{p}$. This advantage can be exploited to tailor the folding behavior by designing crashboxes with local regions having weak or no adhesion. This is one of the next research activities.

2. Similar behavior is observed for the variation of $F_{m}$ with the adhesion strength. With both rates, in the case of no adhesion, the reduction in $F_{m}$ reaches approximately $50 \%$, which is a significant difference, despite the fact that the materials and thicknesses used in both cases are identical. As a result, the $E A$ in, e.g., the dynamic loading for the crashboxes with no adhesion $\left(F_{m} \times \delta_{\max }=33 \mathrm{kN} \times 120 \mathrm{~mm}=3.9 \mathrm{~kJ}\right)$ is $>60 \%$ less than that of the crashboxes with strong adhesion $\left(f_{m} \times \delta_{\text {max }}=69 \mathrm{kN} \times 158 \mathrm{~mm}=\right.$ $10.9 \mathrm{~kJ})$, as shown in Figure $5 \mathrm{c}-\mathrm{e}$. Based on this comparison, another result is that most of the applied $K E$ is transferred into progressive folding for the strong adhesion condition $(K E=11 \mathrm{~kJ})$. However, for the specimen without adhesion, most of $K E$ $(5.4 \mathrm{~kJ})$ is inefficiently consumed by these crashboxes. Information about $K E$ can be found in Table 2.

3. Moreover, the difference in $F_{m}$ in the case of the weak adhesion is only $<10 \%$ compared to the "strong adhesion" case.

4. Additionally, due to the strain rate dependence of the SPS materials, the dynamic $F_{m}$ to the quasi-static $F_{m}$ ratio is approximately 1.2-1.3 regardless of the adhesion condition, as given by the term " $\mathrm{R}$ " in the right column of Table 3 . This is the same ratio found earlier from the tensile tests at different strain rates for investigating the strain rate dependency of the materials used [5].

5. Not only are the axial crushing forces $\left(F_{p}\right.$ and $\left.F_{m}\right)$ significantly affected by varied adhesions, but so is the displacement for the progressive folding, i.e., $\delta_{\text {max }}$. The progressive folding behavior of the crash boxes with the strong adhesion is described in detail in [5]. As mentioned in Equation (1), EA depends on that displacement to the same extent as $F_{m}$. It is found, for the crashboxes without adhesion, that the folding sequence is hindered after forming approx. two folds and global buckling appears. With this, the axial crushing is stopped. As a result, $\delta_{\text {max }}$ is reduced by $47 \%$ and $24 \%$ in the case of quasi-static and highly dynamic loading rates, respectively. This result can be shown clearly with the help of photographic representation of the collapse sequence (see Figures 2 and A1) for the quasi-static and dynamic conditions, respectively. It is be observed that, at $\delta \sim 80 \mathrm{~mm}$, the crashboxes without adhesion could not form any further folds. However, the crashboxes with strong adhesion could be progressively folded up to $>160 \mathrm{~mm}$, delivering approx. seven complete folds compared to only two to three folds for the ones without adhesion. Due to the extreme instability of the crashboxes without adhesion, they slid during the highly dynamic test; this is shown by the sudden increase in force at the end of the force-displacement diagram in Figure 5b.

The observed failure modes are described in Figure 6. In this figure, three crashboxes for each adhesion condition are presented at the end of the dynamic crushing test, where the whole applied KE is absorbed, to show the arising failure modes and their reproducibility. Most of these failure modes did not appear during the quasi-static test, as the test was stopped when the progressive folding is hindered. These failure modes can be described as follows:

1. Two-sided folding from the upper and bottom ends of the crashbox, as shown in Figure 6a and Figure A2a in Appendix A, which is accompanied with delamination in the flange and interlaminar delamination between the steel and polymer layers.

2. Side-sliding and falling down of the crashboxes could also be observed, as shown in Crashbox\#1 in Figure 6a. 
3. Global buckling, which is very remarkable for the crashboxes without adhesion, as shown in Crashbox\#3 in Figure 6a. This failure mode was observed for the crashboxes with weak adhesion, but at greater displacement (see Figure 6a and Table 2). For instance, the crashboxes with the weak adhesion showed only a $\sim 10 \%$ reduction in $\delta_{\max }$, as with the forces.

4. Delamination at flange, which was observed for all the tested cases. This is due to the nature of the used gluing/riveting method, where they may not possess the satisfactory peel and shear resistance necessary to withstand such highly dynamic loading rates. Traditional joining by welding of such SPS sheets is challenging; therefore, mechanical/chemical methods were applied.

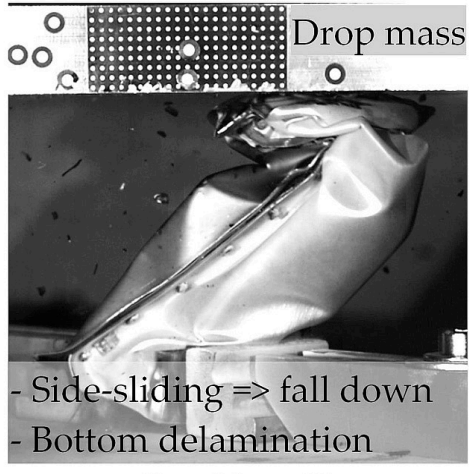

Crashbox \#1

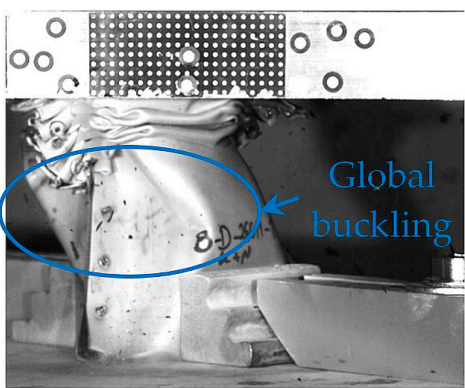

Crashbox \#1

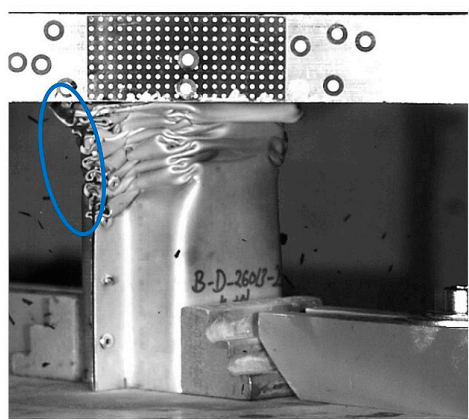

Crashbox \#1

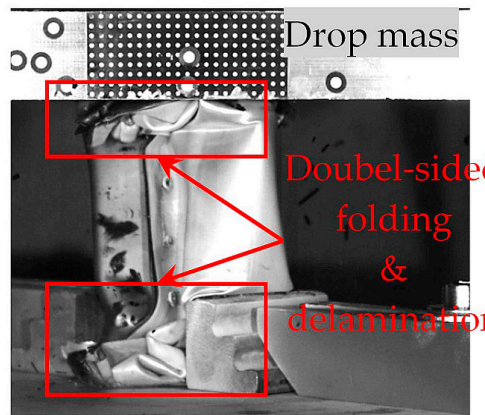

Crashbox $\# 2$

(a)

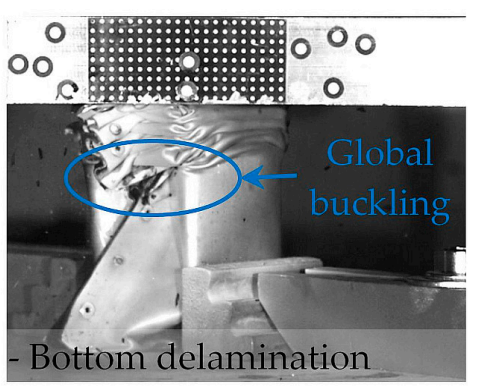

Crashbox \#2

(b)

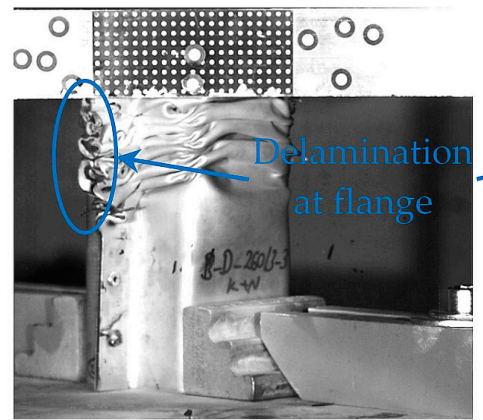

Crashbox \#2

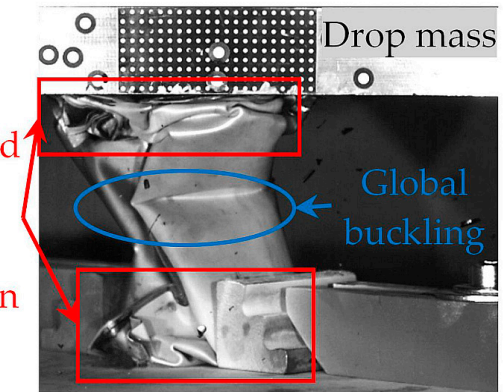

Crashbox \#3

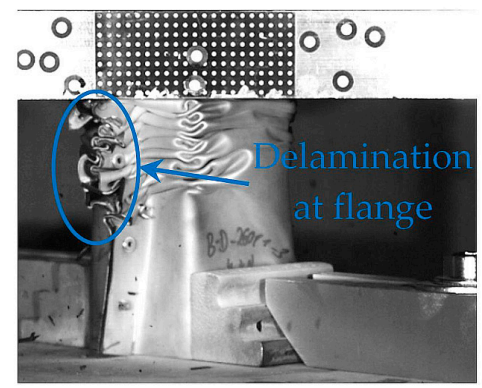

Crashbox \#3

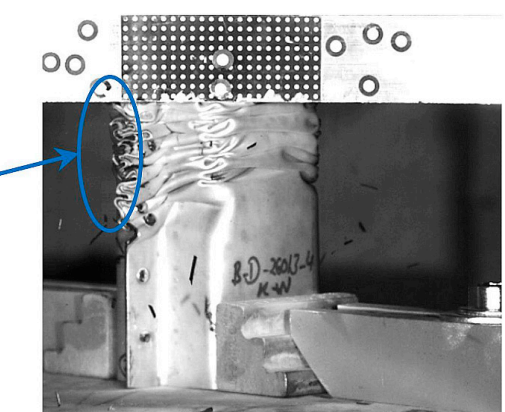

Crashbox \#3

(c)

Figure 6. Failure modes of the dynamic axial crushing test of the double-hat crashboxes (a) without, (b) with weak, and (c) with strong adhesion strength. Three crashboxes per condition are depicted at the end of the crushing test. 
From the axial crushing results, it can be stated that, although the value of the adhesion strength in the case of weak adhesion (5.2 MPa) is about $50 \%$ of the strong adhesion $(10.7 \mathrm{MPa})$, the difference in the crushing behavior, including the forming forces and displacement, is not of the same significance, where only a $10 \%$ reduction could be observed. Moreover, the failure modes were very similar to ones of the strong adhesion. Therefore, this adhesion strength may be sufficient to deliver satisfactory crushing properties. This point can be an advantage in the case of process deviations during the SPS production. The main challenge would appear during the bending of such flat SPS sheets into hat shapes, where delamination and higher springback angles have to be considered.

\subsection{Three-Point Bending Test Results}

For the bending tests, the following characteristic values are evaluated, compared and correlated with the adhesion strength:

1. The energy absorption at a common displacement: in order to evaluate and compare the bending energy in both the quasi-static and dynamic loading rates, a common displacement of $\delta=50 \mathrm{~mm}$ is selected, where sufficient plastic deformation could take place, i.e., forming of at least one central fold. The results are shown in Figure 7 and listed in Table 4. For this purpose, the quasi-static bending tests are carried out firstly, and with the help of the $E A$, in this case, the $E A$ (drop mass and its height) needed for the dynamic test can be then estimated. The energy is determined according to Equation (1).

2. Maximum displacement $\delta_{\text {max }}$ : this is determined for the dynamic bending test only, where the displacement is determined after applying the $K E$, which can be correlated to the adhesion condition.

3. The springback $\Delta \delta$ : this is the difference in the bending displacement just before and after unloading in both the quasi-static and dynamic loading conditions.

Table 4. Summary of the three-point bending test results.

\begin{tabular}{|c|c|c|c|c|c|c|c|c|c|c|c|}
\hline \multirow{3}{*}{$\begin{array}{c}\text { Test } \\
\text { Condition }\end{array}$} & \multicolumn{3}{|c|}{ Quasi-Static Rate } & \multicolumn{7}{|c|}{ Highly Dynamic Rate } & \multirow{3}{*}{$R^{5}$} \\
\hline & \multicolumn{2}{|c|}{$E A[\mathrm{~kJ}]^{1}$} & \multirow{2}{*}{$\Delta \delta[\mathrm{mm}]^{3}$} & \multicolumn{2}{|c|}{$E A[\mathrm{~kJ}]^{1}$} & \multirow{2}{*}{ Mass $[g]^{7}$} & \multicolumn{2}{|c|}{$S E A[\mathrm{~J} / \mathrm{g}]^{6}$} & \multirow{2}{*}{$\begin{array}{c}\delta_{\max } \\
{[\mathrm{mm}]^{4}}\end{array}$} & \multirow{2}{*}{$\Delta \delta[\mathrm{mm}]^{2}$} & \\
\hline & Value & $\Delta^{2}$ & & Value & $\Delta^{2}$ & & Value & $\Delta^{2}$ & & & \\
\hline $\begin{array}{l}\text { SPS, Strong } \\
\text { adhesion }\end{array}$ & $0.74 \pm 0.04$ & Ref. & $4.9 \pm 0.2$ & $0.80 \pm 0.01$ & Ref. & 800 & 1.0 & Ref. & $57 \pm 0.2$ & $5.8 \pm 0.5$ & 1.09 \\
\hline $\begin{array}{c}\text { SPS, Weak } \\
\text { adhesion }\end{array}$ & $0.68 \pm 0.03$ & $-7 \%$ & $5.5 \pm 0.5$ & $0.73 \pm 0.01$ & $-9 \%$ & 794 & 0.92 & $-9 \%$ & $60 \pm 0.8$ & $6.3 \pm 0.4$ & 1.07 \\
\hline $\begin{array}{l}\text { SPS, No } \\
\text { adhesion }\end{array}$ & $0.23 \pm 0.01$ & $-68 \%$ & $6.2 \pm 0.6$ & $0.27 \pm 0.02$ & $-66 \%$ & 793 & 0.34 & $-65 \%$ & $79 \pm 8$ & $10.3 \pm 1.5$ & 1.16 \\
\hline $\begin{array}{c}\text { Steel sheet, } \\
0.48 \mathrm{~mm}\end{array}$ & - & - & - & $0.17 \pm 0.01$ & - & 352 & 0.47 & $-53 \%$ & $67 \pm 2$ & $5.4 \pm 0.1$ & - \\
\hline
\end{tabular}

1: Energy absorbed $E A$ at $\delta=50 \mathrm{~mm}[\mathrm{~kJ}],{ }^{2}$ : Springback value: $\Delta \delta=\delta_{\text {loaded }}-\delta_{\text {unloaded }}{ }^{3}$ : Reduction $\%=>\cdot \Delta$ [\%] $=100 \cdot($ Value-Ref. value $) /$ Ref. value, ${ }^{4}$ : Maximum displacement as a result of the input. $K E,{ }^{5}: R=$ (Dynamic energy/Quasi-static energy) ratio, ${ }^{6}$ : $S E A=E A$ at $\delta=50 \mathrm{~mm} /$ Mass of the crashbox, ${ }^{7}$ : The actual mass of the crashbox, including the mass of the joining materials (rivets and the $3 \mathrm{M}$ glue). The given value is the average of the tested crashboxes. 
Quasi-static bending results

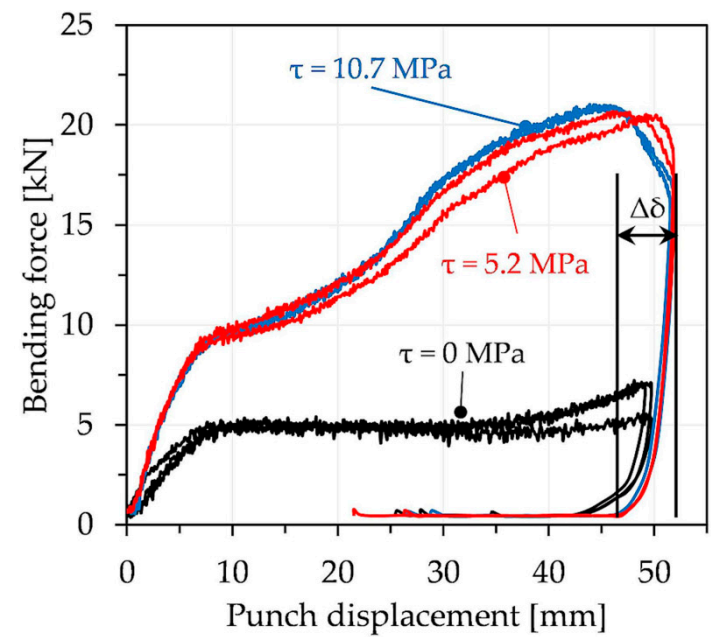

(a)

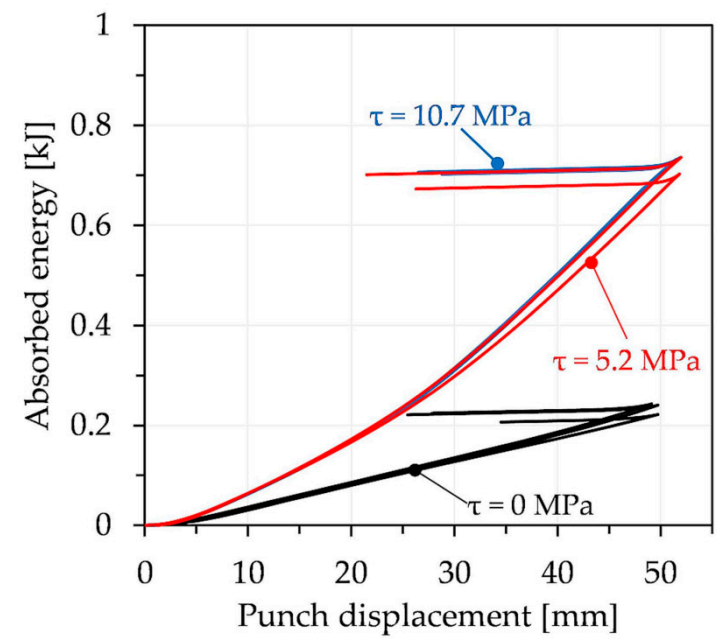

(c)

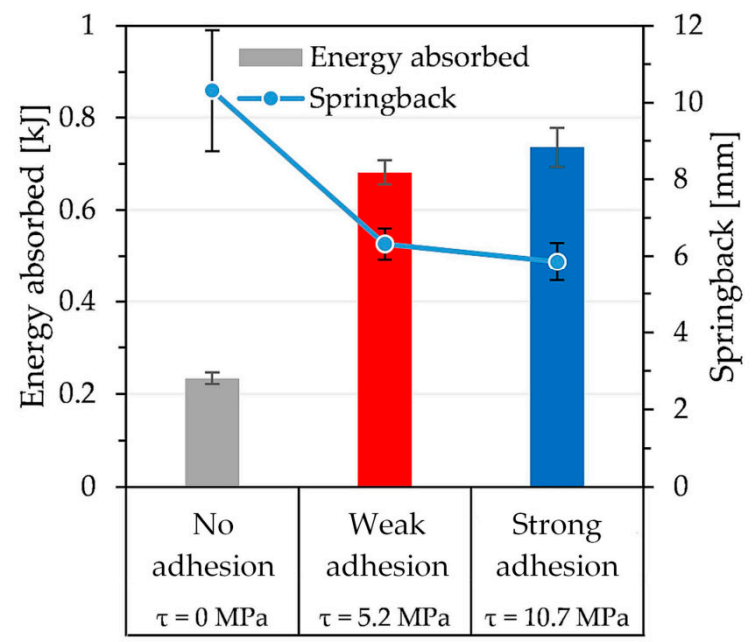

(e)
Dynamic bending results

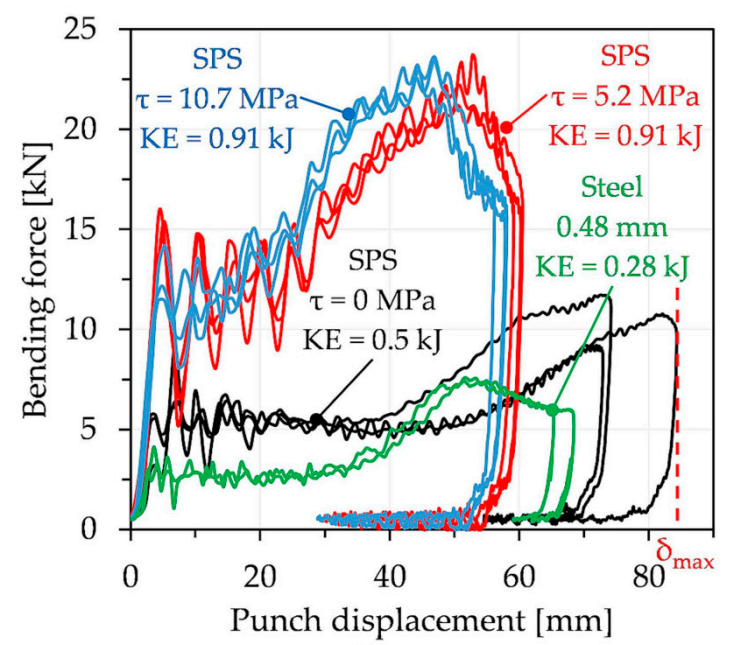

(b)

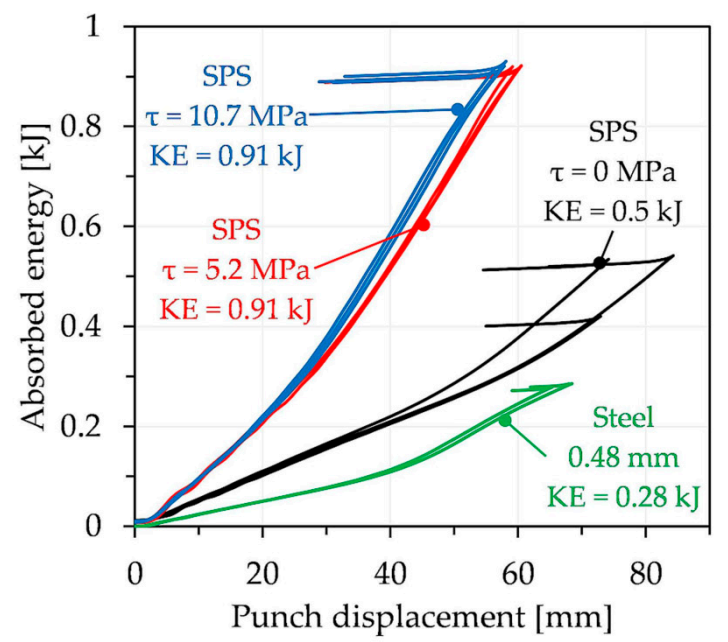

(d)

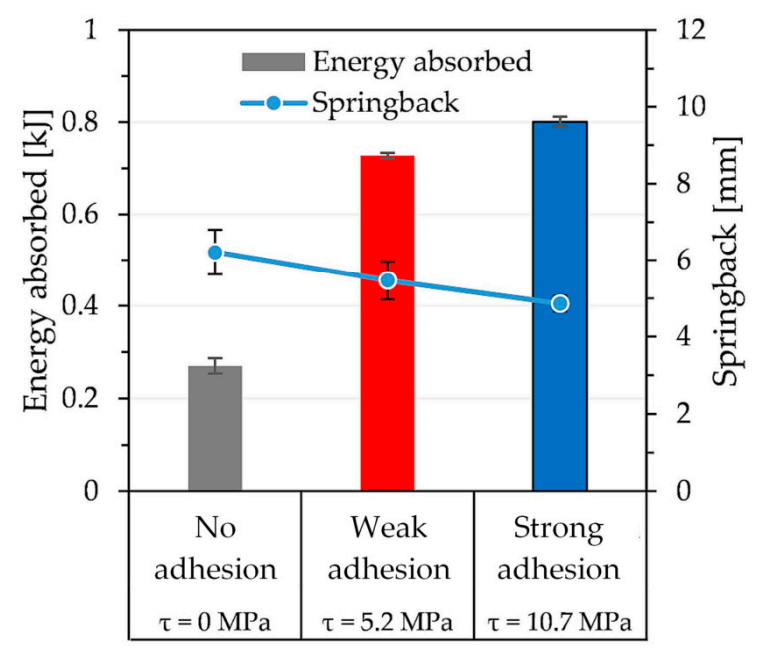

(f)

Figure 7. Three-point bending test results of the top-hat crashboxes in terms of the absorbed energy at the quasi-static (a,c) and the dynamic $(\mathbf{b}, \mathbf{d})$ loading rates, as well as a summary of the results at a punch displacement of $\delta=50 \mathrm{~mm}$ in $(\mathbf{e}, \mathbf{f})$ the springback results. 
Based on these characteristic values, the following results can be stated and discussed:

1. At the common displacement of $\delta=50 \mathrm{~mm}$, the negative influence of the adhesion strength on EA for the top-hat crashboxes without steel/polymer adhesion is substantial. So, for the crashboxes without adhesion, EA is reduced by $68 \%$ and $66 \%$ for the quasi-static and highly dynamic loading rates, respectively, as given in Table 4.

2. The influence of the adhesion can be further highlighted by comparing the dynamic bending behavior of the top-hat crashbox without adhesion with the crashboxes made of only one layer of the steel sheet $(0.48 \mathrm{~mm})$, as shown from the green lines in Figure $7 \mathrm{~b}$,d. At $\delta=50 \mathrm{~mm}$, the $E A$ for the SPS is $0.27 \mathrm{~kJ}$, which is only $0.1 \mathrm{~kJ}$ $(\sim 59 \%)$ higher than for the steel sheet. On the other side, the crashbox with the strong adhesion needs $0.8 \mathrm{~kJ}$ to be deformed to the same displacement $(50 \mathrm{~mm})$. This confirms that the adhesion strength is critical, as it significantly affects the integrity of the three SPS layers, the load conveying capability, and accordingly, the structural stiffness and strength, as well as the energy absorption potential. The energy results are summarized additionally in Figure 7e.

3. Additionally, by comparing the specific energy absorbed $(S E A=E A /$ mass of the crashbox) of the crashboxes without adhesion with the one of only the steel sheet, it was found that the crashboxes without adhesion exhibit less $S E A(0.34 \mathrm{~J} / \mathrm{g})$ not only than those with better adhesion conditions (weak $(0.92 \mathrm{~J} / \mathrm{g}$ ) or strong $(1.0 \mathrm{~J} / \mathrm{g})$ ), but also than the crashboxes of only the steel sheets $(0.47 \mathrm{~J} / \mathrm{g})$. These results confirm once more the importance of improving/maximizing the adhesion strength of the SPS in order to maximize the energy absorption. Moreover, the SEA of the crashboxes of the strong adhesion is at least $50 \%$ better than that of the crashbox of the steel sheet, which is, in fact, the motivation of designing crashboxes out of the SPS sheets as an innovative alternative to monolithic steel sheets.

4. In the highly dynamic test, $\delta_{\max }$-keeping KE the same-is affected as well; for the weak or no adhesion, $\delta_{\max }$ is higher as the force level is decreased. For instance, the crashboxes with weak adhesion show a $\delta_{\max }$ of $60 \mathrm{~mm}$ compared to $57 \mathrm{~mm}$ for the strong adhesion at the same $K E$ of $0.91 \mathrm{~kJ}$. Despite the lower $K E$ of $0.5 \mathrm{~kJ}$ applied on the SPS without adhesion, $\delta_{\max }$ is much higher, at approximately $80 \mathrm{~mm}$.

5. Regarding the springback $\Delta \delta$ results, the absence of adhesion or even weak adhesion leads to a higher $\Delta \delta$, which is in coincidence with the previous results, especially the V-die bending results shown in Section 2.1. Therefore, for crashboxes without adhesion, $\cdot \Delta \delta$ can reach $10 \mathrm{~mm}$, which is approximately $13 \%$ of $\delta_{\max }\left(100 \cdot \Delta \delta / \delta_{\max }\right)$ (see Figure 7e). In the other cases of strong or weak adhesion, the springback was approximately $10 \%$. The failure images before and after unloading are shown in Figures 3 and A4 in Appendix A.

6. Additionally, the structural stiffness was evaluated by determining the slope of the force-displacement curve in the elastic region, i.e., up to a $\delta=10 \mathrm{~mm}$ in the quasi-static loading rate in in Figure 7a,b. The structural stiffness of the top-hat crashboxes with strong adhesion and weak one was comparable of $1.3 \pm 0.1 \mathrm{~N} / \mathrm{m}$. However, resembling the other results, the structural stiffness of the crashboxes without adhesion is only $0.6 \pm 0.1 \mathrm{~N} / \mathrm{m}$, which is approximately $50 \%$ of the previous ones.

7. In addition to $\cdot \Delta \delta$ and $E A$, the failure mode in correlation with the adhesion strength is also different, as shown in Figures 3 and A4 for the quasi-static and highly dynamic rates, respectively. The curvature of the central fold in contact with the bending punch is larger than that ones in the other two conditions (weak and strong adhesion), which shows less structural strength and accordingly less forming force. Moreover, secondary folds are formed with the higher adhesion strength, which results in the force increase shown from the force-displacement curves in Figure 7a,b starting at a displacement of $30 \mathrm{~mm}$. 


\section{Conclusions}

In previous studies, the influence of the adhesion conditions on the level of standard test specimens was specified, where a negative influence concerning the forming limit curve and deep drawability were found. In the current study, the knowledge is extended to cover the structural level on component size. Therefore, the influence of the steel/polymer adhesion strengths on the structural properties of top-hat and double-hat crashboxes under bending and axial crushing test conditions, respectively, are studied. For this purpose, the adhesion strengths were tailored by varying the curing conditions of the adhesive agent, delivering three levels: none, weak, and strong adhesion quality. Based on the performed experiments at quasi-static and highly dynamic loading rates, the following conclusions can be drawn:

1. On the standard specimen level in the V-die bending test, as well as on the structural level, the adhesion strengths show a significant influence on the energy absorption and springback. For instance, the bending force required to bend the SPS sheets with the strong adhesion is more than five times higher than for the one without adhesion.

2. For the crashboxes without adhesion between the steel and polymer, the following characteristic differences can be stated:

a. Although the materials used are identical, more than 50\% less energy absorption takes place regardless of the test configuration (axial crushing and bending) and its rate (highly dynamic and quasi-static).

b. Under axial crushing loading, less structural stability and hindered folding progress are dominant; for instance, a maximum number of two to three folds can be formed under axial crushing test conditions. Further failure modes, such as delamination and side-sliding/falling down, also take place.

c. Under the bending conditions, despite the lower density of the crashboxes made of the $1.56 \mathrm{~mm}$ SPS sheets and their higher thickness compared to the crashboxes made of the $0.48 \mathrm{~mm}$ steel sheet, the crashboxes without adhesion absorbed significantly less SEA than the crashboxes made of only steel sheet. Therefore, the steel crashboxes absorbed $0.47 \mathrm{~J} / \mathrm{g}$; however, the crashboxes without adhesion absorbed only $0.34 \mathrm{~J} / \mathrm{g}$. However, the SPS crashboxes with the strong adhesion $(1 \mathrm{~J} / \mathrm{g})$ absorbed $200 \% S E A$, as with the steel crashboxes $(0.47 \mathrm{~J} / \mathrm{g})$.

3. Although, for weak adhesion conditions, the lap shear strength is reduced by approximately $50 \%$, i.e., from $10.7 \mathrm{MPa}$ for the strong adhesion condition to $5.2 \mathrm{MPa}$ for the weak condition, only a small negative influence - up to $10 \%$ - on the absorbed energy and a minor effect on the failure mode are observed. Therefore, it can be stated that the lap shear strength of approximately five to six MPa could be satisfactory for achieving comparable structural properties to the crashboxes with the strong adhesion properties.

4. The bending structural stiffness of the crashboxes with the weak adhesion was approximately the same as the one with the strong adhesion $(1.3 \mathrm{~N} / \mathrm{m})$, which is two times that of the specimen without adhesion $(0.6 \mathrm{~N} / \mathrm{m})$.

These investigations will be extended by finite element analysis with the explicit solver of LS-DYNA, which is well suited for modeling impact and crash loading conditions. The focus in these studies will be the consideration of interlaminar/adhesive properties between metal and polymer by means of using advanced cohesive zone modeling approaches that also include plasticity and strain rate dependency. This will help to better understand and optimize the crushing behavior of such crashboxes and create predictive models.

Author Contributions: Conceptualization, M.H., M.K., J.R., A.H., M.G., and H.P.; methodology, M.H., M.K., J.R., and A.H.; software, M.H., M.K., J.R., and A.H.; validation, M.H., M.K., J.R., and A.H.; formal analysis, M.H., M.K., J.R., and A.H.; investigation, M.H., M.K., J.R., and A.H.; re-sources, M.G. and H.P.; data curation, M.H., M.K., J.R., and A.H.; writing-original draft preparation, M.H., M.K., and J.R.; writing—review and editing, A.H., M.G., and H.P.; visualization, M.H., M.K., J.R., 
and A.H.; supervision, M.G. and H.P.; project administration, M.G. and H.P.; funding acquisition, M.G. and H.P. All authors have read and agreed to the published version of the manuscript.

Funding: This research was funded by the German Research Foundation, DFG project number 407352905.

Institutional Review Board Statement: Not applicable.

Informed Consent Statement: Not applicable.

Data Availability Statement: Data available on request due to restrictions, e.g., privacy or ethical.

Acknowledgments: We acknowledge the financial support by the DFG and the Open Access Publishing Fund of the Clausthal University of Technology. Moreover, we thank thyssenkrupp Steel Europe GmbH for supplying the steel sheets and BSc And Fynn Matschullat (TU Clausthal) for his support during the experimental work.

Conflicts of Interest: The authors declare no conflict of interest.

\section{Appendix A}

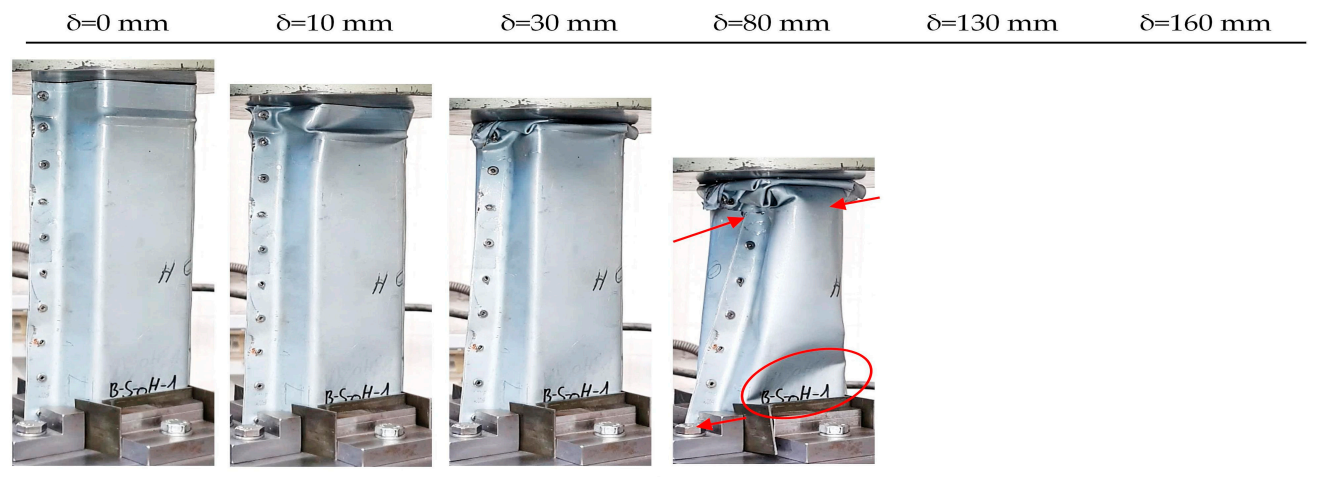

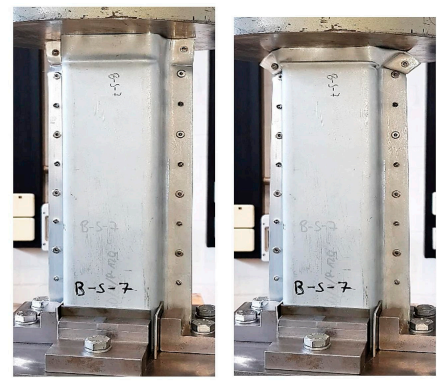

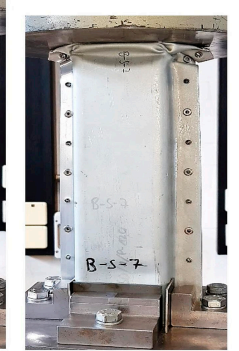

(a)
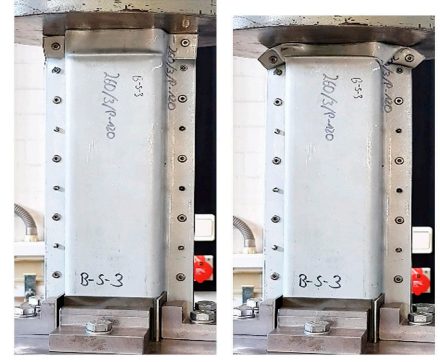

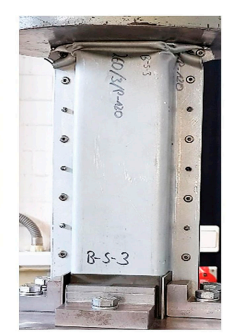

(b)
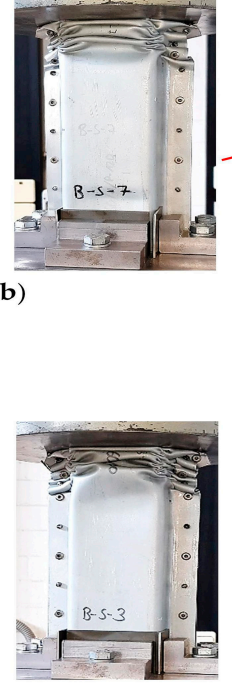

(c)
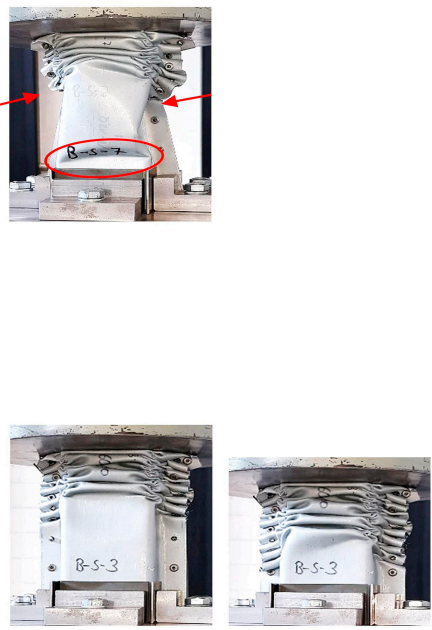

Figure A1. Photographic presentation of the quasi-static collapse progress at different time steps for the double-hat crashboxes (a) without, (b) with weak and (c) with the strong adhesion strength. 


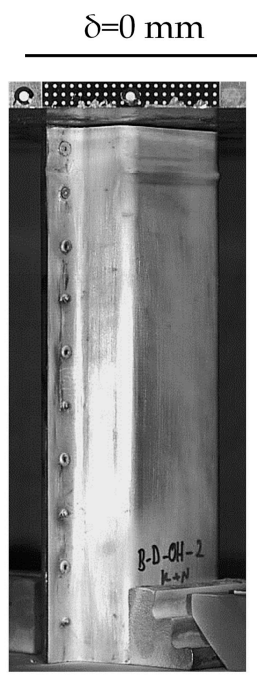

$0 \mathrm{~ms}$

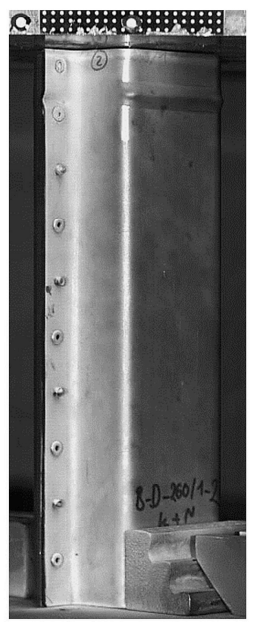

$0 \mathrm{~ms}$

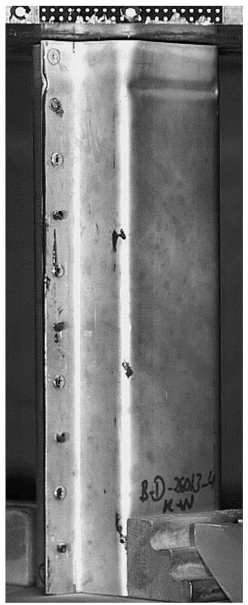

$0 \mathrm{~ms}$ $\delta=10 \mathrm{~mm}$

$\delta=30 \mathrm{~mm}$

$\delta=80 \mathrm{~mm}$

$\delta=130 \mathrm{~mm}$

@ $\delta_{\max }$

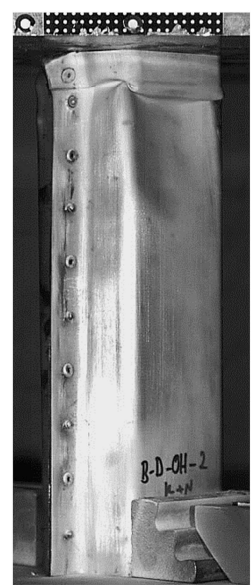

$1.4 \mathrm{~ms}$

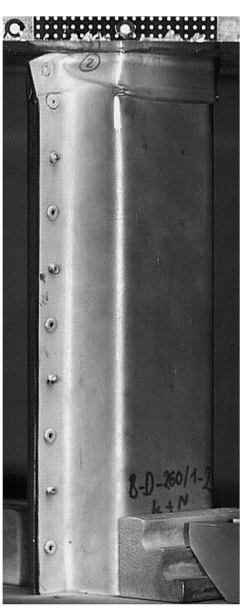

$1.2 \mathrm{~ms}$

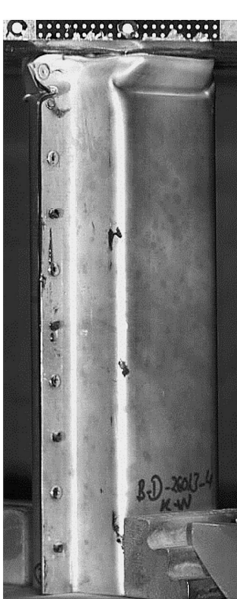

$1.2 \mathrm{~ms}$

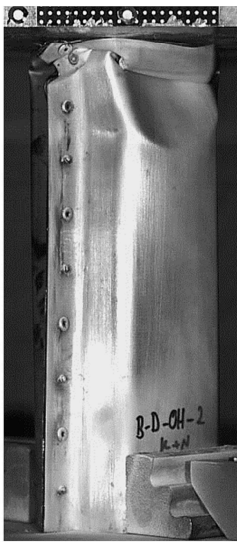

$4.2 \mathrm{~ms}$

(a)

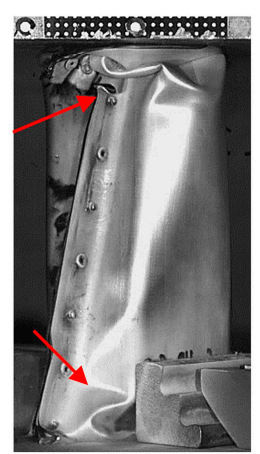

$12.6 \mathrm{~ms}$

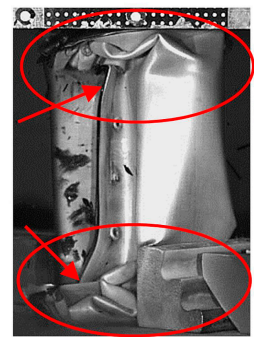

$24.6 \mathrm{~ms}$

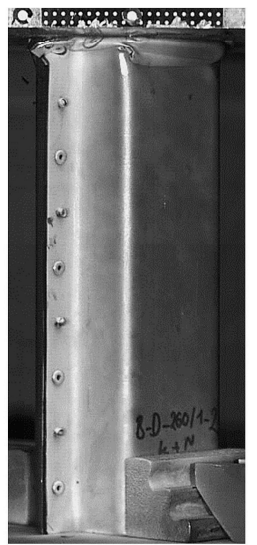

$3.8 \mathrm{~ms}$

(b)

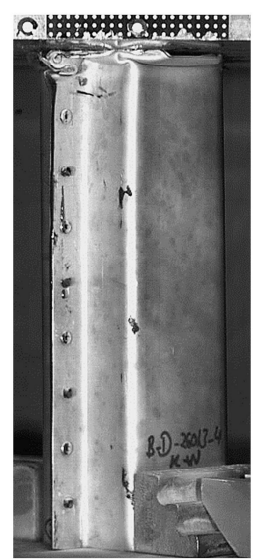

$3.8 \mathrm{~ms}$

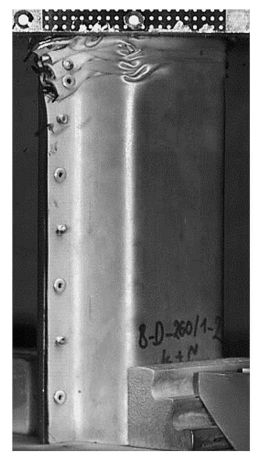

$11.2 \mathrm{~ms}$

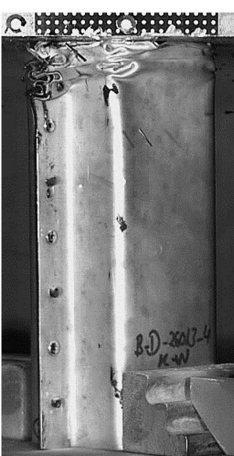

$11.4 \mathrm{~ms}$

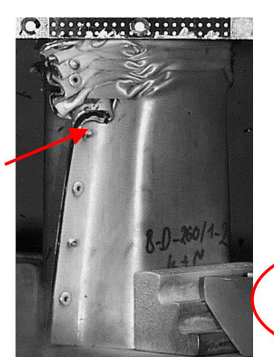

$20.8 \mathrm{~ms}$

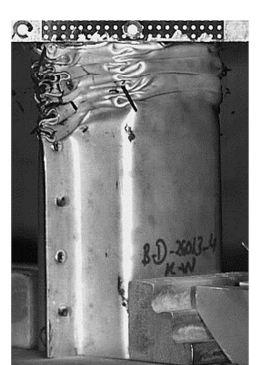

$21.8 \mathrm{~ms}$

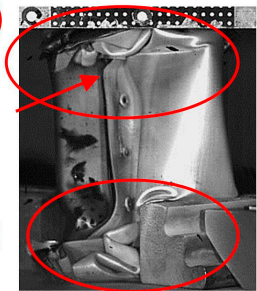

$39.6 \mathrm{~ms}$

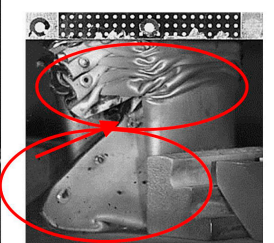

$52.6 \mathrm{~ms}$

(c)

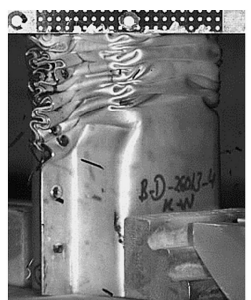

$38.4 \mathrm{~ms}$

Figure 2. Photographic presentation of the dynamic collapse progress at different time steps for the double-hat crashboxes (a) without, (b) with weak, and (c) with strong adhesion strength. 

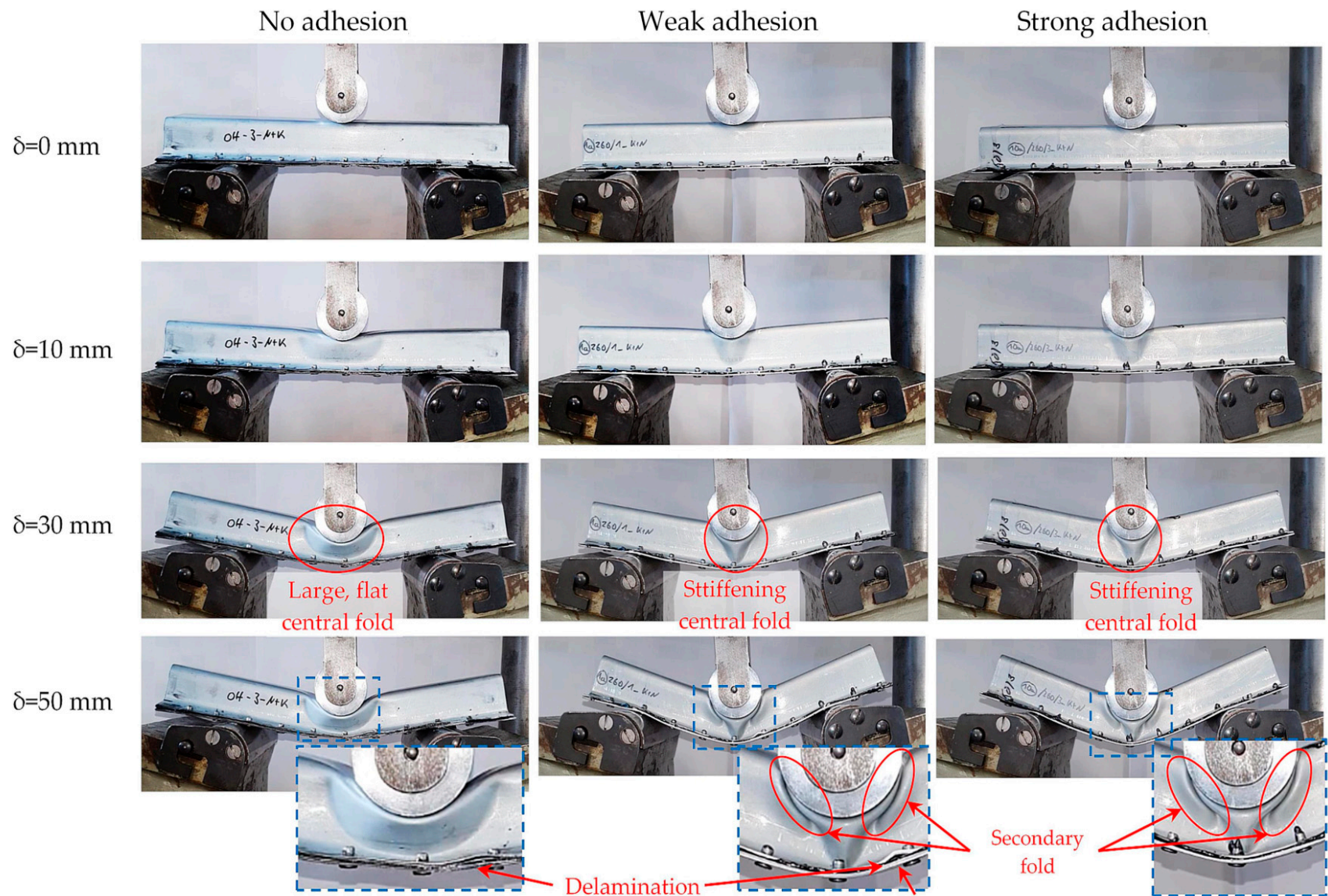

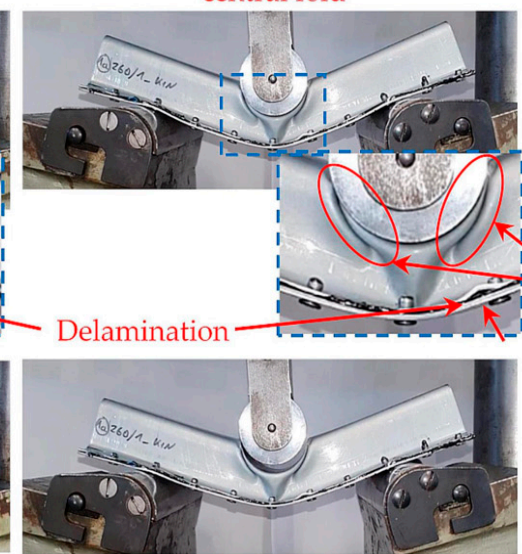

(b)

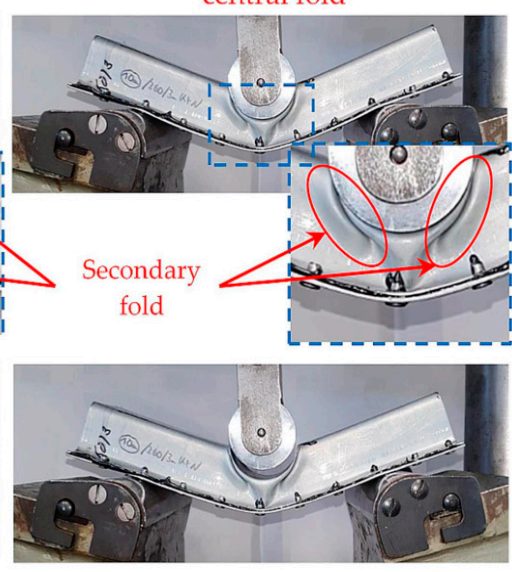

(c)

Figure 3. Photographic presentation of quasi-static bending behavior at different time steps for the top-hat crashboxes (a) without, (b) with weak, and (c) with strong adhesion strength. 


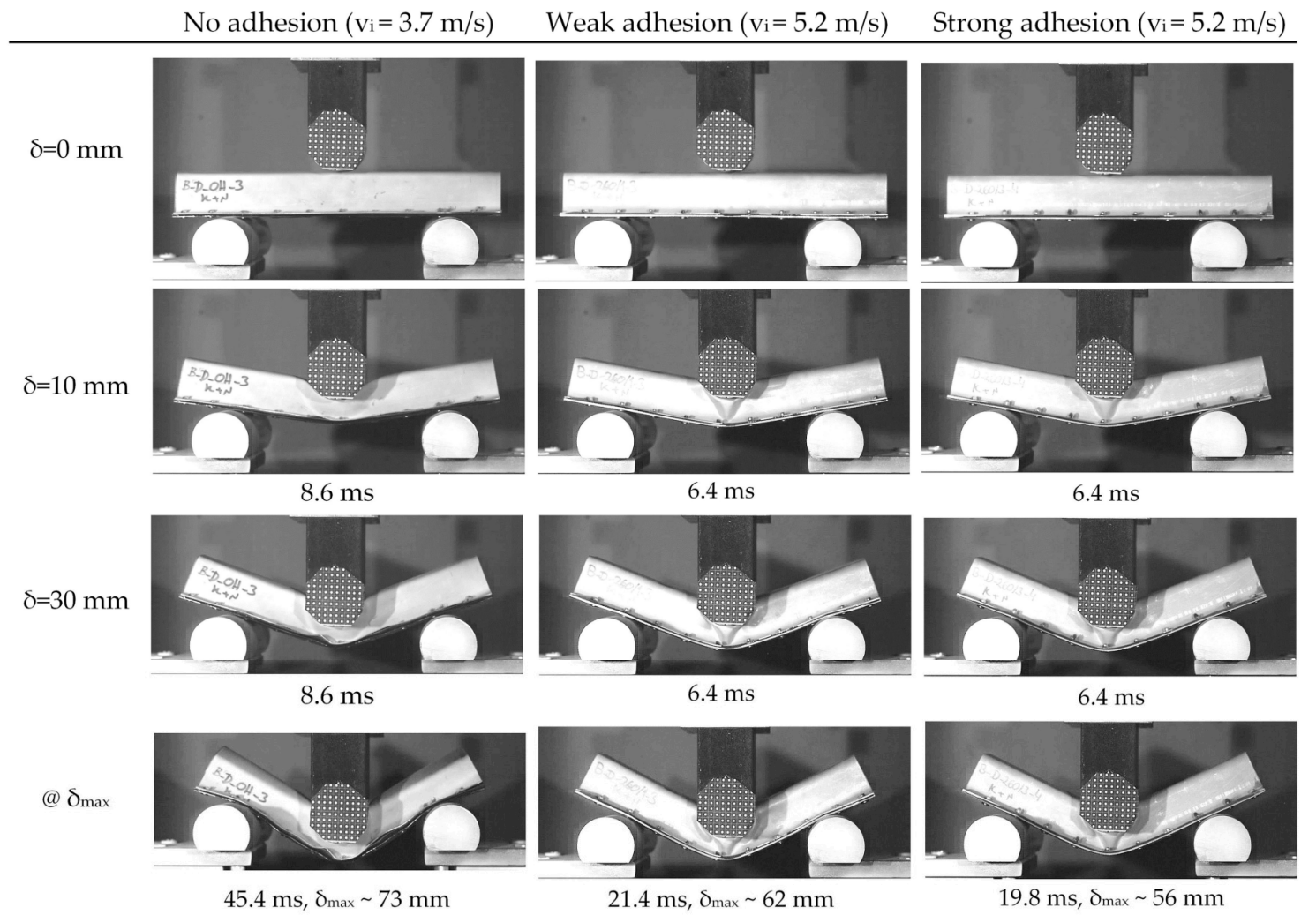

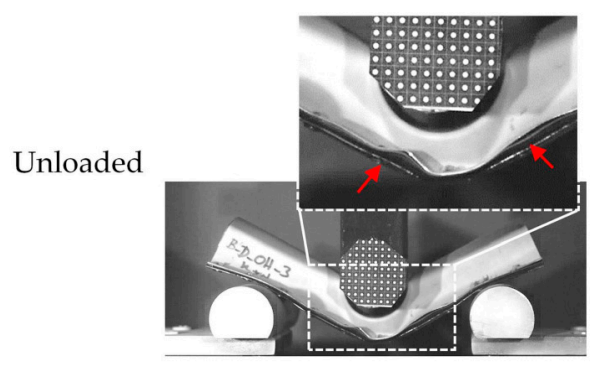

(a)

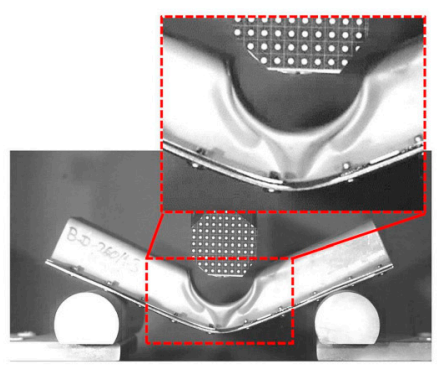

(b)

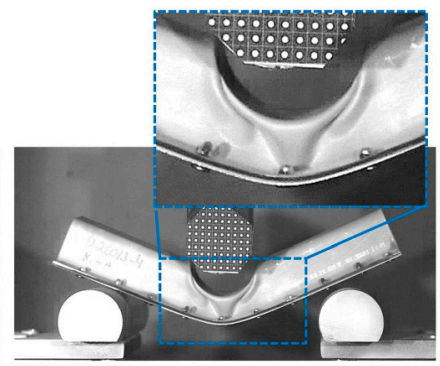

(c)

Figure A4. Photographic presentation of dynamic bending behavior at different time steps for the top-hat crashboxes (a) without, (b) with weak, and (c) with strong adhesion strength.

\section{References}

1. Keßler, L.; Dams, R.; Marx, A.; Theiss, M. Erweiterung der Simulation für die virtuelle Fertigungskette von Sandwich-Werkstoffen am Beispiel LITECOR®. In Tagungsband des 35. EFB-Kolloquiums Blechverarbeitung; 1. Aufl.; Blechverarbeitung, E.F., Ed.; EFB: Hannover, Germany, 2015; pp. 33-42. ISBN 3867764522.

2. Ferkel, H.; Patberg, L.; Rauhut, M.; Mendelin, C. Neue und wiederendeckte Perspektiven von Stahl. In 1. Niedersächsisches Symposium Materialtechnik, 12-13.02.2015, Clausthal-Zellerfeld; 1. Aufl.; Wiche, H., Wesling, V., Teichmann, C., Eds.; Shaker: Herzogenrath, Germany, 2015; pp. 2-7. ISBN 384403403X.

3. Druesne, F.; Hamdaoui, M.; Yin, Q.; Daya, E.M. Variability Analysis of Modal Characteristics of Frequency-Dependent ViscoElastic Three-Layered Sandwich Beams With Spatial Random Geometrical and Material Properties. J. Vib. Acoust. $2017,139$. [CrossRef]

4. Sharma, S. Sandwich Steels for Crash Energy Absorption Applications. Ph.D. Thesis, University of Warwick, Warwick, UK, 2014.

5. Harhash, M.; Kuhtz, M.; Richter, J.; Hornig, A.; Gude, M.; Palkowski, H. Trigger geometry influencing the failure modes in steel/polymer/steel sandwich crashboxes: Experimental and numerical evaluation. Compos. Struct. 2021, 262, 113619. [CrossRef]

6. Pieronek, D.; Kessler, L.; Richter, H.; Myslowicki, S. Virtuelle Produktentwicklung und Crashauslegung von StahlWerkstoffverbundsystemen. In 14. Deutsches LS-DYNA Forum, Bamberg, Germany; 10-12.10.2016; DYNAmore GmbH: Stuttgart, Germany, 2016.

7. Liu, J.; Liu, W.; WANG, J. Influence of interfacial adhesion strength on formability of AA5052/polyethylene/AA5052 sandwich sheet. Trans. Nonferrous Met. Soc. China 2012, 22, s395-s401. [CrossRef] 
8. Han, S.; Sung, M.; Jang, J.; Jeon, S.-Y.; Yu, W.-R. The effects of adhesion on the tensile strength of steel-polymer sandwich composites. Adv. Compos. Mater. 2020, 1-19. [CrossRef]

9. Satheeshkumar, V.; Yadav, A.; Narayanan, R.G. Formability Prediction and Springback Evaluation of Adhesive-Bonded Steel Sheets. In Advances in Material Forming and Joining; Narayanan, R.G., Dixit, U.S., Eds.; Springer: New Delhi, India, 2015; pp. 61-80. ISBN 978-81-322-2354-2.

10. Satheeshkumar, V.; Narayanan, R.G. Formability of adhesive-bonded steel sheets with artificial finite adhesive defects. J. Strain Anal. Eng. 2014, 49, 286-300. [CrossRef]

11. Satheeshkumar, V.; Narayanan, R.G. Experimental evaluation and prediction of deep drawability of adhesive bonded steel sheets. Mater. Werkst. 2015, 46, 713-735. [CrossRef]

12. Harhash, M. Forming Behaviour of Multilayer Metal/Polymer/Metal Systems. Ph.D. Thesis, TU Clausthal, Clausthal-Zellerfeld, Germany, 2017.

13. Kuhtz, M.; Hornig, A.; Gude, M.; Jäger, H. A method to control delaminations in composites for adjusted energy dissipation characteristics. Mater. Des. 2017, 123, 103-111. [CrossRef]

14. DIN EN 10346:2009-07. Continuously Hot-Dip Coated Steel Flat Products-Technical Delivery Conditions; German Version; Beuth Verlag GmbH: Berlin, Germany, 2009.

15. Richter, J.; Kuhtz, M.; Hornig, A.; Harhash, M.; Palkowski, H.; Gude, M. A Mixed Numerical-Experimental Method to Characterize Metal-Polymer Interfaces for Crash Applications. Metals 2021, 11, 818. [CrossRef]

16. Jandel, A.-S.; Meuthen, B. Coil Coating: Bandbeschichtung: Verfahren, Produkte und Märkte; 3., überarb. und aktualisierte Aufl.; Springer Vieweg: Wiesbaden, Germany, 2013; ISBN 3834823546.

17. Harhash, M.; Sokolova, O.; Carradò, A.; Palkowski, H. Mechanical properties and forming behaviour of laminated steel/polymer sandwich systems with local inlays-Part 1. Compos. Struct. 2014, 118, 112-120. [CrossRef] 